\title{
La cultura del pacto en las relaciones diplomáticas luso-castellanas durante el período Trastámara (1369-1504) ${ }^{1}$
}

\author{
The Culture of the Pact in Portuguese-Castilian Diplomatic Relations during \\ the Trastámara Period (1369-1504)
}

\author{
David Nogales Rincón \\ Fundación Española para la Ciencia y la Tecnología - Universidade de Lisboa \\ davidnogalesrincon@gmail.com
}

\begin{abstract}
RESUMEN
El período Trastámara dio forma a una cada vez más consolidada cultura del pacto en el marco de las relaciones políticas entre las cortes reales medievales, que se manifestó en un interés creciente por la diplomacia y en el impulso a la noción de guerra justa. En este trabajo se intentarán analizar, desde la perspectiva específica de las relaciones diplomáticas entre la corte castellana y portuguesa, la realidad de la cultura del pacto a través del análisis del léxico de la negociación y del acuerdo, de los espacios, prácticas e instrumentos de la negociación, de los argumentos legitimadores de tales prácticas o de su representación en torno a las diversas fórmulas de tratamiento y ceremoniales, en el período comprendido entre los años 1369 y 1504.
\end{abstract}

Palabras clave: Castilla. Portugal. Trastámaras. Avís. Realeza. Diplomacia. Pacto. Guerra.

\begin{abstract}
The Trastámara period shaped and consolidated a culture of the pact in the framework of political relations among royal medieval courts, manifested in a growing interest in diplomacy and in the impulse towards the notion of a just war. From the specific perspective of diplomatic relations between the Castilian and Portuguese courts between 1369 and 1504, this study examines the reality of the culture of the pact through an analysis of the lexicon of negotiation and agreement, the spaces, practices and instruments of negotiation, as well as the legitimating arguments of such practices and their representation in connection with the diverse forms of address and ceremonies.
\end{abstract}

Key words: Castile. Portugal. Trastámaras. Avís. Kingship. Diplomacy. Pact. War.

Sumario: 1. Introducción. 2. Las dinámicas del pacto. 3. Legitimación del conflicto: la guerra justa. 4. La cultura del pacto: ideología, prácticas e instrumentos. 4.1. El léxico del pacto y del acuerdo. 4.2. Los argumentos legitimadores del pacto. 4.3. Las modalidades del pacto: treguas, paces, alianzas, matrimonios. 4.4. El espacio de la negociación. 5. Los oficiales de la diplomacia. 6. La representación del pacto. 6.1. Las fórmulas de tratamiento. 6.2. La dimensión ceremonial. 7. Conclusiones.

1 Este trabajo ha sido posible gracias a una ayuda para la investigación postdoctoral, concedida por Ministerio de Educación de España, mediante el Programa Nacional de Movilidad de Recursos Humanos del Plan Nacional de I+D+i 2008-2011, como investigador contratado de la FECYT, con vinculación al Centro de Historia de la Facultad de Letras de la Universidad de Lisboa. Dicho trabajo forma parte igualmente del Proyecto de Investigación, financiado por el Ministerio de Ciencia e Innovación de España, $n^{\circ}$ HAR2010-16762, titulado: "Prácticas de consenso y de pacto e instrumentos de representación en la cultura política castellana (siglos XIII al XV)", dirigido por José Manuel Nieto Soria. 


\section{INTRODUCCIÓN}

La potenciación del uso de la diplomacia en Occidente a fines de la Edad Media fue fruto de la convergencia de un conjunto diverso de factores: la experiencia de la Guerra de los Cien Años, el Cisma de Occidente y la afirmación del Estado moderno, desarrollados de una forma paralela al proceso de valorización de las teorías sobre la guerra justa $^{2}$, la cada vez más nítida definición de un cuerpo legal con pretensiones de universalidad $^{3}$ y ciertas dinámicas políticas regionales, como la llegada al trono castellano de la dinastía Trastámara, que implicó el desarrollo de una línea política exterior con "claros objetivos, continuidad en su realización y la aplicación de todos los medios materiales necesarios para ella"4. La cercanía del reino de Portugal y sus estrechas relaciones familiares y políticas con Castilla facilitaron que el reino vecino se constituyera en uno de los referentes principales de la política exterior de la corte castellana durante la segunda mitad del trescientos y todo el cuatrocientos, en el marco del creciente interés por el recurso a la embajada como instrumento de relación política ${ }^{5}$ de lo que no sería erróneo probablemente considerar como una consolidación del pacto y del acuerdo como vía prioritaria de acción política ${ }^{6}$.

\section{LAS DINÁMICAS DEL PACTO}

La segunda mitad del siglo XIV y todo el siglo XV se presenta desde la perspectiva de las relaciones luso-castellanas como un período caracterizado por la alternancia de conflictos armados de diversa intensidad y de largos períodos de paz, articulados por los dos grandes enfrentamientos armados culminados en la derrota castellana de Aljubarrota (1385) y en la portuguesa de Toro (1476) y por los acuerdos de paz que los siguieron, sustanciados respectivamente en el tratado de paz firmado en Medina del Campo en

${ }^{2}$ Mattoso, J.; Sousa, A.: A monarquía feudal (1096-1480), Lisboa, 1994, p. 524.

${ }^{3}$ Cf. Mattingly, G.: La diplomacia del Renacimiento, Madrid, 1970, pp. 47-60.

4 Díaz, L.V.: "Los inicios de la política internacional de Castilla (1360-1410)", en Realidad e imágenes del poder. España a fines de la Edad Media, Valladolid, 1988, pp. 57-83, p. 69.

${ }^{5}$ El número de embajadas en el período 1320-1470 superó el centenar, es decir, una media de una embajada cada año y medio, sin olvidar los encuentros protagonizados personalmente por los propios monarcas. Cf. MARQues, A.H.O.: “As relações diplomáticas”, en Actas das II Jornadas Luso-Espanholas de História Medieval, Oporto, 1987, 4 vols., vol. I, pp. 39-58, pp. 50-52. Sólo durante el reinado de Alfonso V, Saul António Lopes ha contabilizado, hasta 1474, setenta y cuatro misiones diplomáticas enviadas al extranjero, entre las cuales Castilla ocuparía un lugar prioritario, con un número total de veinticinco. Cf. Gomes, S.A.: D. Afonso V O Africano (1432-1481), Lisboa, 2009, p. 147.

${ }^{6}$ El estudio del pacto, del consenso y de la negociación constituye un tema de creciente interés en el ámbito hispánico, con buenos ejemplos en los trabajos reunidos en: FERRER, M.T. et alii: Negociar en la Edad Media/Négocier au Moyen Âge, Barcelona, 2005; CArrasco, A.I.; ForondA, F.: Du contrat d'alliance au contrat politique: cultures et sociétés politiques dans la Péninsule Ibérique de la fin du Moyen Âge, Toulouse, 2007; CARrasco, A.I.; Foronda, F. (dirs.): El contrato político en la Corona de Castilla: cultura y sociedad políticas entre los siglos X al XVI, Madrid, 2008; ForondA, F.: Avant le contrat social: Le contrat politique dans l'Occident médiéval XIIIe-XVe siècle, París, 2011, así como los recopilados en el no 11 (2010) de Edad Media: Revista de Historia (Valladolid), cuyo dossier monográfico se encuentra dedicado a "La resolución de las diferencias: poder, conflicto y consenso". 
1431, ratificado en Almeirim en 1432, y en el tratado de Alcáçovas firmado en 1479, ratificado en Toledo en $1480^{7}$.

En un primer nivel, las alianzas entre ambos reinos vinieron marcadas, en no pocas ocasiones, por la estrecha vinculación existente entre las dinámicas políticas internas y la dirección de la acción exterior de los respectivos reinos. Así lo expondría el cronista castellano Andrés Bernáldez, al referir que en los inicios del reinado de Isabel I de Castilla (1474-1504) "muchas embajadas fueron e vinieron de los cavalleros de Castilla, de la liga de la Señora Dona Juana, particulares y generales al rey D. Alonso de Portugal, convidándole con ella para casar, e con Castilla para reinar"'. Ello era consecuencia del interés que para los bandos en liza había de tener el establecimiento de alianzas con ciertas instancias de poder del reino vecino, proceso facilitado desde el ámbito castellano quizá por la presencia de exiliados portugueses y por la existencia de vínculos de parentesco entre una y otra corona'. Buena muestra de estas conexiones

7 Para una cronología detallada sobre las diversas embajadas, alianzas, tratados y matrimonios en el período véase: Brandẽo, F. de C.: História diplomática de Portugal. Uma cronologia, Lisboa, 2002, pp. 33-69; LóPEZ, J.: Repertorio diplomático español. Índice de los tratados ajustados por España (11251935) y de otros documentos internacionales, Madrid, 1944, pp. 31-41; VISCONDE DE SANTAREM: Quadro elementar das relações políticas e diplomáticas de Portugal, París, 1842, 18 vols., vol. I, pp. 213-394 y vol. II, pp. 1-28; Noticia dos embaixadores e ministros enviados por D. Manuel a diversas cortes da Europa e dos que estas the mandaram, Biblioteca Nacional de Portugal (BNP), Reservados, Cod. 411, fols. 1r-10r. Aproximaciones de carácter interpretativo en: MARTínez, P.S.: História diplomática de Portugal, Lisboa, 1986, pp. 49-62, 83-88; GonzÁlez, M.: "Las relaciones entre Portugal y Castilla en el siglo XV (1411-1474)", en El Tratado de Tordesillas y su época, Valladolid, 1995, 3 vols., vol. II, pp. 781-792; García Fitz, F.: "Nuevos desencuentros. Las paces de Alcoutim (1371) y Santarém (1373)", en Encontros e desencontros. Tratados hispano-portugueses desde a Idade Média, Lisboa; Barcelona; Madrid, 2006, pp. 51-61; Álvarez Palenzuela, V.Á.: "Las relaciones castellano-portuguesas en el panorama político internacional", en Jornadas de Cultura Hispano-portuguesa, Madrid, 1999, pp. 33-50; Homem, A.L.C.: "Depois de Aljubarrota: os tratados de Trancoso (1387) e Bayonne (1388)", en Encontros e desencontros..., pp. 63-71; SuÁrez, L.: "Capitulaciones matrimoniales entre Castilla y Portugal en el siglo XIV (1373-1383)", en Hispania (Madrid), 33 (1948), pp. 531-561; Olivera, C.: Beatriz de Portugal. La pugna dinástica Avis-Trastámara, Santiago de Compostela, 2005, especialmente pp. 47-193; MendonçA, M.: "As relações com Castela no século XV", en El Tratado de Tordesillas..., vol. II, pp. 835-847; NovoA, F.: "Consolidar la paz, ganar nuevos mundos: el Tratado de Medina de Campo-Almeirim (1431)", en Encontros e desencontros..., pp. 73-87; FonSECA, L.A. da: Alguns aspectos das relações diplomáticas entre Portugal e Castela em meados do século XV (1449-1456), Oporto, 1973; SuÁRez, L.: Relaciones entre Portugal y Castilla en época del Infante don Enrique (1393-1460), Madrid, 1960, pp. 16-68; Romero, P.: Dos monarquías medievales ante la modernidad. Relaciones entre Portugal y Castilla (1431-1479), La Coruña, 1999; Álvarez Palenzuela, V.Á.: "Objetivos y proyectos en las relaciones castellano-portuguesas", en Castilla y el mundo feudal. Homenaje al profesor Julio Valdeón, Valladolid, 2009, 2 vols., vol. II, pp. 457-477, pp. 473-477; Moreno, H.C.B.: "As relações entre Portugal e Castela em torno de 1492", en Las relaciones entre Portugal y Castilla en la época de los Descubrimientos y la expansión colonial, Salamanca, 1994, pp. 53-61; AraúJo, J.M.A.A.: Portugal e Castela (1431-1475). Ritmos de uma paz vigilante, tesis de doctorado, Faculdade de Letras, Universidade de Lisboa, 2003, 2 vols., objeto de reciente publicación bajo el título Portugal e Castela na Idade Media, Lisboa, 2009.

${ }^{8}$ Bernáldez, A.: Historia de los Reyes Católicos D. Fernando y Dña. Isabel. Crónica inédita del siglo $X V$, Granada, 1856, 2 vols., vol. I, cap. XVI, p. 50.

${ }^{9}$ La idea de la existencia de un "partido portugués en Castilla integrado por varias familias de origen lusitano" ha sido apuntada en Romero, P.: "Apoyo del partido portugués a una política pro-lusitana en Castilla durante el siglo XV", en Castilla y el mundo feudal...., vol. II, pp. 665-677; Idem: "Cuando los 'portugueses' gobernaban en Castilla. Siglo XV", en La Península Ibérica entre el Mediterráneo y el 
en los tiempos tempranos de la dinastía Trastámara puede encontrarse en la alianza de la oposición petrista con Fernando I de Portugal (1367-1383), o en la de Juan I de Castilla (1379-1390) con el "partido" portugués de Leonor Téllez. No obstante, como ha llamado la atención Luís Adão da Fonseca en relación con Castilla, el gran momento en el proceso de internacionalización de los conflictos internos castellanos se hubo de producir con ocasión del conocido como Golpe de Tordesillas de $1420^{10}$. Durante las décadas siguientes veremos así cómo la convulsa política interna castellana marcará buena parte de las relaciones externas de Castilla con Portugal: la búsqueda, en el marco de las paces de 1431, del apoyo portugués frente a los Infantes de Aragón ${ }^{11}$; pasando por la alianza, sellada a través del matrimonio de Juan II de Castilla (1406-1454) con Isabel de Portugal contratado en 1447 entre don Álvaro de Luna y el infante don Pedro, duque de Coimbra, a su vez enfrentado con el "partido" de la reina portuguesa doña Leonor, viuda del rey don Duarte de Portugal (1433-1438) y hermana de los Infantes de Aragón ${ }^{12}$; hasta la fijación de la alianza entre Alfonso V de Portugal (1438-1481) y el sector favorable a doña Juana de Castilla, hija de Enrique IV (1454-1474), en el marco de la lucha por la conquista del trono castellano tras la muerte de Enrique IV, en $1474^{13}$. Por otro lado, este juego de alianzas no fue ajeno a la problemática del equilibrio ibérico, con relación al cual la carta portuguesa se presentaba, en el juego de las relaciones peninsulares, como un conveniente contrapeso frente a la hegemonía aragonesa. Así hubo de suceder con el tratado de alianza ofensiva firmado en Santarén entre Fernando I de Portugal y Enrique II de Castilla (1369-1379), el 19 de marzo de 1374, contra Pedro IV de Aragón (1336-1387) ${ }^{14}$; con el referido matrimonio contratado entre Juan II de Castilla e Isabel de Portugal frente al poder representado por los Infantes de Aragón ${ }^{15}$; o con la búsqueda, por parte de Enrique IV, bajo la influencia del Marqués de Villena, de la alianza portuguesa, como contrapeso, primero, a las posibles pretensiones del rey de Aragón con el apoyo del partido de los Infantes y, después, a la alianza aragonesa establecida por la infanta doña Isabel de Castilla a través de su matrimonio con el rey de

Atlántico. Siglos XIII-XV, Sevilla; Cádiz, 2006, pp. 695-702, con una posición crítica a dicha opinión en Olivera, C.: "Los exiliados portugueses en la Castilla de los Trastámara: cultura contractual y conflicto dinástico", en El contrato...., pp. 323-353, pp. 332-334, 352.

${ }^{10}$ Fonseca, L.A. DA: O Tratado de Tordesilhas e a Diplomacia Luso-Castelhana no século XV, Lisboa, 1991, pp. 21-22.

11 AraúJo, J.M.A.A.: Portugal..., vol. I, pp. 115-116.

12 Cf. AraúJo, J.M.A.A.: Portugal..., vol. I, pp. 263-290; SuÁrez, L.: Relaciones..., pp. 53-62; Romero, P.: Dos monarquías..., pp. 110-111.

13 Araúuo, J.M.A.A.: Portugal..., vol. I, pp, 416-430.

${ }^{14}$ Brandão, F. de C.: História..., p. 35.

15 SuÁrez, L.: "Relaciones diplomáticas entre Portugal y Castilla en la Edad Media", en $1^{a}$ Jornadas Académicas de História da Espanha e de Portugal, Lisboa, 1990, pp. 215-233, p. 232; Romero, P.: Dos monarquías..., pp. 105-112. 
Sicilia, Fernando, en $1469^{16}$. Asimismo, las propias dinámicas entre Castilla y Portugal no fueron ocasionalmente ajenas a la problemática política general de Occidente ${ }^{17}$.

En un segundo nivel, la negociación se impuso como instrumento genérico para la consecución de la paz, para la disensión de la confrontación o para la consecución de la mera neutralidad del reino vecino, aspectos de especial interés en contextos políticos caracterizados por su inestabilidad (minorías, conflictos políticos internos) o por el desarrollo de empresas políticas o militares concretas ${ }^{18}$. En tales momentos la negociación no sólo podía poner fin a la confrontación bélica, sino que permitía cerrar, en contextos específicos, crisis de legitimidad, al ser reconocidos estatus concretos de soberanía hasta entonces discutidos ${ }^{19}$.

\section{LEGITIMACIÓN DEL CONFLICTO: LA GUERRA JUSTA}

Uno de los apoyos más claros para el desarrollo de la vía diplomática en el período bajomedieval fue la noción, tantas veces expresada, que consideraba la paz y la unidad como bienes supremos ${ }^{20}$. Ello desembocó, a través de un proceso que cabe sospechar complejo, entre otros posibles aspectos, en la definición de la noción de guerra justa ${ }^{21}$, una de cuyas consecuencias fue la necesidad de presentar argumentos justificativos de

${ }^{16}$ SuÁrez, L.: “Relaciones...”, p. 232; MACEDO, J.B. de: História diplomática portuguesa. Constantes e linhas de força, Lisboa, 1987, p. 62; VAL, I. del: "El matrimonio como instrumento político. Dos acuerdos matrimoniales para la futura Isabel I de Castilla", en Sociedad y memoria en la Edad Media: estudios en homenaje de Nilda Guglielmi, Buenos Aires, 2005, pp. 107-117, p. 109; Romero, P.: "Apoyo del partido....", p. 668.

17 Cf. SuÁrez, L.: “Capitulaciones...”, pp. 560-561; SÁnchez Sesa, R.: "El Cisma de Occidente en la Península Ibérica: religión y propaganda en la guerra castellano-portuguesa", en Estudos em homenagem ao professor doutor José Marques, Oporto, 2006, 4 vols., vol. IV, pp. 307-320, especialmente pp. 307312 .

18 Crónicas de los Reyes de Castilla: desde don Alfonso el Sabio hasta los Católicos don Fernando y doña Isabel, Madrid, 1953, 3 vols., vol. II, año 1392, cap. XIV, p. 200; Ibid., vol. II, año 1431, cap. XXV, p. 501; AraúJo, J.M.A.A.: Portugal..., vol. I, pp. 62, 85; Ayala, C. de; Villalba, F.J.: "Precedentes lejanos de la crisis de 1383: circunstancias políticas que acompañan al Tratado de Santarem", en Actas das II Jornadas Luso-Espanholas..., vol. I, pp. 233-245, p. 245; Archivo Municipal de Murcia (AMM), Cartas Reales (CR), de 1391 a 1412, fols. 145v-146r (1411-V-30, Valladolid) en SuÁrEZ, L.: Relaciones..., doc. 44, p.176; Romero, P.: Dos monarquías..., p. 127; FonseCA, L.A. da: Alguns aspectos..., p. 36; Zurara, G.E. de: Crónica da tomada de Ceuta, ed. de Reis Brasil, Lisboa, 1992, cap. V, p. 49.

19 ANTT, Livro das Demarcações e Pazes, fols. 142r y ss. (1431-X-30, Medina del Campo) en Monumenta Henricina, Coimbra, 1960-1974, 15 vols., vol. IV, doc. 9, pp. 24-26; ANTT, gav. 18, maç. 8, num. 16 (1479-IX-4, Alcáçovas) en Documentos..., vol. I, no 166, p. 294. Cf. Olivera, C.: Beatriz de Portugal, pp. 186-190; Romero, P.: Dos monarquías..., p. 70.

20 Algunas ideas en torno a esta noción de la paz se pueden encontrar en: BAYONA, B.: "La paz en la obra de Marsilio de Padua", en Contrastes (Málaga), 11 (2006), pp. 44-63; Rodríguez Velasco, J.D.: "Pax: hablar sobre la paz en la Edad Media", en La guerra en la Edad Media. XVII Semana de Estudios Medievales, Logroño, 2007, pp. 405-434; Belloso, N.: "Sobre la guerra y la paz en Alfonso de Madrigal", La Corónica (Nueva York), 33:1 (2004), pp. 17-38.

${ }^{21}$ Definiciones sobre esta noción pueden encontrarse en: Ordinações Afonsinas, Coimbra, 1792, ed. facsímil, Lisboa, 1984, lib. I, título LI, p. 285; Alfonso X: Las Siete Partidas, Madrid, 1807, 3 vols., part. II, tít. XXIII, ley I, p. 227; LóPEZ DE SEgovia, J.: De la Confederación de Príncipes y de la guerra y de los guerreros, Madrid, 1931, pp. 83-90. 
la acción armada. Entre tales argumentos cabría citar, en primer lugar, la invocación a lo sagrado. La problemática del Cisma ofreció una valiosa baza en el impulso a los móviles de tipo eclesiástico ${ }^{22}$. Cuando ello no fue posible, tal invocación se realizó bajo la impronta de la profecía y del mesianismo que encontró, con motivo de la entrada en Castilla de Alfonso V de Portugal, en 1475, un campo fértil, en tanto que "los a él afiçionados avían lugar de le publicar por el "encubierto"'23 y que "segund la pronosticaçión de los sanctos padres por la qual paresçen los reynos de Castilla aver de ser seguros al reyno de Portugal"24. De una forma ordinaria, por su capacidad para otorgar tintes religiosos a las empresas bélicas, hubieron de tener especial relieve las rogativas y las ceremonias religiosas de acción de gracias. En segundo lugar, cabría aludir a la exposición, en obras de naturaleza genérica diversa (informes jurídicos, tratados históricos, arengas, etc.), de un conjunto de derechos, fundados sobre la Historia, la Genealogía o el Derecho, susceptibles de respaldar las pretensiones soberanas sobre el reino vecino. La corte castellana fue especialmente activa en esta dirección, con buenos ejemplos en el comentario de Alonso de Cartagena defendiendo la soberanía castellana sobre las islas Canarias frente a Portugal en Allegationes super conquesta Insularum Canariae contra Portugalenses (1437) ${ }^{25}$, en la epístola de Diego Rodríguez de Almela Árbol de la genealogía de los reyes que en el regno de Portogal han regnado $(1478)^{26}$, en el anónimo memorial Relación del derecho que la Reyna Cathólica tiene al Reyno de Portugal (1494) ${ }^{27}$, o, entrando ya en el terreno del providencialismo, en la literaria Divina retribución sobre la caída de España (1479), del bachiller de sobrenombre Pal$\mathrm{ma}^{28}$. Del lado portugués, cabe destacar la línea legitimista desarrollada por Fernando I

${ }_{22}$ Lopes, F.: Crónica de D. Fernando, Lisboa, 2004, cap. CLIII, p. 532; Idem: Crónica de D. João I, Oporto, 1990, 2 vols., vol. II, cap. XLI, p. 104. Cf. ArAúJo, J.M.A.A.: Portugal..., vol. I, p. 38; SÁnChEZ SESA, R.: "El Cisma....", pp. 316-317.

${ }^{23}$ Crónica incompleta de los Reyes Católicos, ed. de J. Puyol, Madrid, 1934, cap. XXIII, p. 181. Igualmente: Ibid., cap. L, p. 304.

${ }^{24}$ Valera, D. de: Crónica de los Reyes Católicos, ed. de J. de M. Carriazo, Madrid, 1927, cap. IV, p. 13.

25 Edición en GonzÁlez, T. et alii (eds.): Diplomacia y humanismo en el siglo XV: edición crítica, traducción y notas de las "Allegationes super conquesta Insularum Canariae contra portugalenses" de Alfonso de Cartagena, Madrid, 1994. Sobre este aspecto véase: Romero Portilla, P.: "La rivalidad luso-castellana desde 1415 a 1479 por la legitimidad sobre las tierras conquistadas", en La Península Ibérica en la Era de los Descubrimientos 1391-1492, Sevilla, 1997, 2 vols., vol. II, pp. 1745-1752, pp. 1748-1751; GonzÁlez, T. et alii (eds.), Diplomacia..., 1994, pp. 18-27; Fernández Gallardo, L.: Alonso de Cartagena. Una biografia politica en la Castilla del siglo XV Valladolid, 2002, pp. 185-208.

${ }^{26}$ Biblioteca del Real Monasterio de San Lorenzo de El Escorial (B. Esc.), H-III-15, fols. 104r-107v, con edición del ejemplar conservado en la British Library en: Rodríguez de Almela, D.: Cartas (BL MS Egerton 1173), ed. de D. Mackenzie, Exeter, 1980, pp. 19-28. Sobre este véase: CARRASCO, A.I.: Isabel I de Castilla y la sombra de la ilegitimidad. Propaganda y representación en el conflicto sucesorio (14741482), Madrid, 2006, p. 396; Olivera, C.: Beatriz de Portugal, pp. 411-418.

27 Archivo General de Simancas (AGS), Estado, leg. 367, doc. 142, editado en Szaszdi LeonBorja, I.; Klimes-Szmik, K.: El memorial portugués de 1494. Una alternativa al Tratado de Tordesillas, Madrid, pp. 119-137, con aproximaciones analíticas sobre esta problemática en: OliverA, C.: Beatriz de Portugal, pp. 422-432; Szaszdi Leon-Borja, I.; Klimes-Szmik, K.: El memorial..., pp. 89-102.

28 B. Esc., Y-III-1, editado en BAchiller de Palma, Divina retribución sobre la caída de España en el tiempo del noble rey don Juan el Primero, ed. de J.M. Escudero, Madrid, 1879, con aproximaciones analíticas en: Gómez Redondo, F.: "La Divina retribuçión: discurso político y texto histórico", en Medioevo y Literatura. Actas del V Congreso de la Asociación Hispánica de Literatura Medieval, 
de Portugal en relación con los derechos dinásticos que, como descendiente directo de los reyes de Castilla, tenía al trono castellano frente a Enrique II de Castilla ${ }^{29}$, "dizendo -señala Fernão Lopes- que per morte d'el-rrei dom Pedro seu primo elle era de dereito herdeiro dos rreinos de Castella e de Leom e seu senhor naturall" ${ }^{\prime 30}$, y el discurso pronunciado en las Cortes de Coimbra de 1385 por el jurista João das Regras, probablemente reelaborado, en buena parte, por Fernão Lopes, defendiendo, en detrimento de los derechos de Juan I de Castilla y de su mujer, doña Beatriz, al trono de Portugal, el alzamiento del Maestre de Avís como rey, una vez declarado vacante el trono lusitano ${ }^{31}$. A estos se hubo de sumar, con una dimensión fundamentalmente oral, la exposición de derechos sobre cuestiones específicas, es decir, las "muitas rezoees por cada hũu mostrar sua querella ser boa, e hũa parte dizia que movera justa guerra e a outra tambem que direitamente a fazia", como sucedía con ocasión de las negociaciones entre Castilla y Portugal a fines del siglo XIV ${ }^{32}$. Estas pretensiones de soberanía tuvieron una vía de expresión privilegiada en el plano emblemático -con la disposición de las armas de pretensión sobre pendones, moneda acuñada en cecas específicas o las cotas de los oficiales de armas- y en la intitulación del rey, a la vez que no sería extraño el uso de fórmulas tendentes a deslegitimar las pretensiones del contrincante a través de la fórmula "rey que se llama", por medio de la cual se venía a subjetivar la titulatura adoptada por este.

No fue ajena quizás a este proceso de impulso a las ideas de guerra justa y de potenciación de la orientación negociadora en el marco del conflicto, entreveradas con nociones de dimensión caballeresca, la difusión que, en este período, experimentarían las conocidas como cartas de batalla o carteles de desafio 33 , es decir, "los documentos que escribían y enviaban los caballeros para requerir un combate y acordar sus pormenores" 34 , los cuales eran comunicados a través de los "officiaes de desafio real" ${ }^{35}$.

Granada, 1995, 4 vols., vol. II, pp. 413-431; CARrasco, A.I.: Isabel I de Castilla ..., pp. 362-363, 388390, 397-398; Olivera, C.: Beatriz de Portugal, pp. 418-422.

${ }^{29}$ García Fitz, F.: "Nuevos desencuentros", p. 52; Gomes, R.C.: D. Fernando (1345-1383), Lisboa, 2009, pp. 86-87.

${ }^{30}$ Lopes, F.: Crónica de D. Fernando, cap. XXVIII, p. 97, añadiendo, en otro pasaje, que "e ell assi o dezia, que pois el-rrei dom Pedro era morto, que el ficava erdeiro nos rreinos de Castella e de Leom, ca era bisneto legitimo d'el-rrei dom Sancho de Castella, neto da rrainha dona Beatriz filha do dito rrei dom Sancho", Ibid., cap. XXX, pp. 101-102.

${ }^{31}$ Lopes, F.: Crónica de D. João I, vol. I, caps. CLXXXII-CXCII, pp. 391-424. Cf. Silva, N.E.G. da: "O discurso do doutor João das Regras nas Cortes de Coimbra de 1385. Dúvidas e observações", en Aljubarrota. 600 anos, Lisboa, 1987, pp. 389-420; VIEGAS, V.: "A somenos importância do discurso do doutor João das Regras nas cortes de Coimbra de 1385", en 1383-1385 e a Crise Geral dos Séculos XIV$X V$, Lisboa, 1985, pp. 365-378; Caetano, M.: "As Cortes de 1385", en História do Direito Português (Sécs. XII-XVI), Lisboa, 2000, pp. 445-459; Idem: As Cortes de 1385, Coimbra, 1951, pp. 12-23.

${ }^{32}$ Lopes, F.: Crónica de D. João I, vol. II, cap. CLXXIX, p. 396.

33 Sobre estos Gómez Redondo, F.: Historia de la prosa medieval castellana. III. Los orígenes del humanismo. El marco cultural de Enrique III y Juan II, Madrid, 2002, pp. 2881-2885; OreJudo, A.: Cartas de batalla, Barcelona, 1993, pp. 24-51.

${ }^{34}$ Orejudo, A.: Cartas..., p. 24.

35 PInA, R. de: Chronica d'El-Rei D. Affonso V, Lisboa, 1901, 3 vols., vol. I, cap. LXXVIII, p. 156, quien atribuye la participación a los "arautos e trombetas", con referencias en el ámbito castellano al papel de los reyes de armas en tales actos en: VALERA, D. de: "Preeminencias y cargos de los oficiales de armas", en Penna, M. (ed.): Prosistas castellanos del siglo XV, 2 vols., Madrid, 1959-1964, vol. I, pp. 
Tales testimonios se encuentran bien documentados, en lo que se refiere a nuestro ámbito de estudio, al menos, desde fines del $\mathrm{XIV}^{36}$, con un momento especialmente destacado en el último cuarto del siglo XV, con ocasión del conflicto que enfrentó a Alfonso $\mathrm{V}$ de Portugal con los Reyes Católicos ${ }^{37}$. Desde la orientación que aquí nos interesa, tales cartas y carteles suponían el despliegue de diversos argumentos justificativos de la acción armada y de los derechos que amparaban las pretensiones políticas de aquel que desafiaba a su contrario.

\section{LA CULTURA DEL PACTO: IDEOLOGÍA, PRÁCTICAS E INSTRUMENTOS} 4.1. EL LÉXICO DEL PACTO Y DEL ACUERDO

La cultura del pacto se sustanciará en diversas modalidades de acuerdo ${ }^{38}$, al que se llegaba a través de procesos referidos bajo las fórmulas "acordar" 39 , "concordar" "40, "convenir" ", "contratar"42, "igualar" "43, "concertar" "44, "conformar" $" 45$, "asentar"46 o "avenirse"

169-171, p. 170 y FernÁndez de Oviedo, G.: Libro de la Cámara Real del príncipe don Juan, oficios de su casa y servicio ordinario, ed. de S. Fabregat, Valencia, 2006, p. 153.

${ }^{36}$ Lopes, F.: Crónica de D. João I, vol. II, cap. LIV, pp. 144-145; Ibid., vol. II, cap. CLXIII, pp. 356-358.

37 Carrasco, A.I.: Isabel I de Castilla..., pp. 167-180; Sesma MuÑoz, Á.: "Carteles de batalla cruzados entre Alfonso V de Portugal y Fernando V de Castilla (1475)", en Revista Portuguesa de História (Coimbra), 16 (1976), pp. 277-295, pp. 277-283.

${ }^{38}$ Sobre estos aspectos, véase el apartado "4.3. Las modalidades del pacto: treguas, paces, alianzas, matrimonios".

39 Citaremos, a lo largo de las siguientes páginas, sólo algunos ejemplos de lo que podríamos considerar como un conjunto de términos omnipresentes en la documentación relativa a las negociaciones diplomáticas entre ambas cortes: (9-X-1446, Évora) en SousA, A.C. de: Provas da História Genealógica da Casa Real Portuguesa, Tomo I, Libro III, Coimbra, 1947, $\mathrm{n}^{\circ} 37, \mathrm{p} .189$; Crónicas de los Reyes de Castilla, vol. II, año 1371, cap. VII, pp. 10.

40 Cf. AGS, Patronato Real (PR), leg. 49, doc. 1 (1393-III-01, Lisboa) en SuÁREZ, L.: Relaciones..., doc. 2, p. 72; Lopes, F.: Crónica de D. João I, vol. II, cap. CXL, p. 305; Arquivo Nacional Torre do Tombo (ANTT), gaveta (gav.) 17, maço (maç.) 4, numero (num.) 17 (1494-VI-7, Tordesillas) en Sú́rez, L.; ToRRE, A. de la: Documentos referentes a las relaciones con Portugal durante el reinado de los Reyes Católicos, Valladolid, 1958-1963, 3 vols. [cit. en adelante como Documentos...], vol. II, doc. 463, p. 428; Crónicas de los Reyes de Castilla, vol. II, año 1392, cap. XI, p. 197; Ibid., vol. II, año 1421, cap. XXXIV, p. 411; BARRIENTOS, L.: Refundición de la Crónica del Halconero, ed. de J. de M. Carriazo, Madrid, 1946, cap. I, p. 10.

${ }^{41}$ AGS, Patronato Real (PR), leg. 49, doc. 1 (1393-III-01, Lisboa) en SuÁrEZ, L.: Relaciones..., doc. 2, p. 73; ANTT, gav. 17, maç. 4, núm. 17 (1494-VI-7, Tordesillas) en Documentos..., vol. II, doc. 463, p. 428.

${ }^{42}$ AGS, PR, leg. 49, doc. 8 (1407-VIII-16, Serra da Atouria) en SuÁrez, L.: Relaciones..., doc. 42, p. 171.

${ }^{43}$ AMM, CR, de 1391 a 1412, fols. 145v-146r (1411-V-30, Valladolid) en SuÁrez, L.: Relaciones..., doc. 44, p. 176; Archivo Municipal de Burgos (AMB), Actas, año 1411, fol. 30r (1411-V-30, Valladolid) en Monumenta..., vol. I, doc. 152, p. 350.

44 Resende, G. de: "Vida e Feytos del Rey Dom Ioam Segundo", en Crónica de D. João II e Miscelânea, ed. de J. V. Serrão, Lisboa, 1991, pp. 1-290, cap. CLXVII, p. 243.

${ }^{45}$ Enríquez del Castillo, D.: Crónica de Enrique IV, ed. de A. Sánchez, Valladolid, 1994, cap. 55, p. 208.

${ }^{46}$ AGS, PR, leg. 50, doc. 24 (1490-IV-18, Sevilla) en Documentos..., vol. II, doc. 422, pp. 370, 374; Crónica incompleta..., cap. XXI, p. 172.

${ }^{47}$ Crónicas de los Reyes de Castilla, vol. II, año 1372, cap. V, p. 15. 
El propio acuerdo será, en este sentido, referido como "asiento" 48 , "concordia"49, "capitulación" 50 " "tracto" 51 , "avenencia" ${ }^{2}$ o "concierto" ${ }^{33}$. Todos estos se presentan como términos equiparables, en algún caso con algún matiz añadido ${ }^{54}$. No es extraño que, en estos contextos de acuerdo, se tendiera a enfatizar la firmeza del mismo a través de calificativos asociados a las ideas de verdad y firmeza, tales como "fiel", "leal", "verdadero", "firme" o "estable"

El proceso previo para alcanzar el acuerdo, es decir, la negociación, aparece referida bajo términos como "trabtar ${ }^{56}$-cuya sustantivación, "tracto", no tiene necesariamente un carácter perfectivo, sino que connota también un proceso no cerrado ${ }^{57}$-, "negoçiar" 58 , "falar" 59 -con ocasional distinción de grado entre hablar "em feito de paz" ${ }^{60} \mathrm{o}$ "em tregoa" ${ }^{61}$ - y "razonar", acaso con ciertas connotaciones de carácter competitivo y polémico ${ }^{62}$.

Las actitudes favorables al acuerdo podrían ser fijadas en una gradación que iría desde el deseo de apaciguar una situación de conflicto en el marco de la negociación

${ }^{48}$ AGS, PR, leg. 16, doc. 27 (1480-III-13?) en Documentos..., vol. II, doc. 212, p. 28.

49 Ibid.

${ }^{50}$ AGS, Registro General del Sello (RGS), nº 2848 (1480-III-14, Toledo) en Documentos..., vol. II, doc. 213 , p. 29.

51 AGS, PR, leg. 50, doc. 1 (1480-III-15, Toledo) en Documentos..., vol. II, doc. 215, p. 31, con ocasional referencia, de una forma específica, a su condición de "trapto de la paz" o "trato de las treguas". Cf. ANTT, gav. 18, maç. 11, num. 4 (1423-IV-30, Ávila) en Monumenta..., vol. III, doc. 37, p. 60; AGS, PR, leg. 49, doc. 16 (1423-IX-04, Sintra) en Monumenta..., vol. III, doc. 40, p. 72; AMB, Actas, año 1411, fol. 30r (1411-V-30, Valladolid), en Monumenta..., vol. I, doc. 152, p. 349.

${ }^{52}$ Crónicas de los Reyes de Castilla, vol. II, año 1373, cap. VI, p. 16.

53 Ibid., vol. II, año 1420, cap. XXII, p. 388.

${ }_{54}$ Por ejemplo, si el término "contratar" tiene un matiz específicamente jurídico, "igualar" parece presentarse como sinónimo del acuerdo en el marco de procesos conflictivos de negociación, al aludir al consenso o equilibrio alcanzado en torno a cuestiones concretas sobre las que existían desavenencias. Cf. Lopes, F.: Crónica de D. João I, vol. II, cap. CXCII, pp. 431, 432.

55 ANTT, gav. 18, maç. 11, num. 4 (1423-IV-30, Ávila) en Monumenta..., vol. III, doc. 37, p. 64; ANTT, Livro das Demarcações e Pazes, fols. 142r y ss. (1431-X-30, Medina del Campo) en Monumenta..., vol. IV, doc. 9, p. 23.

56 AMM, CR, de 1391 a 1412, fols. 18r-19r (1399-VI-4, Segovia) en SuÁrEZ, L.: Relaciones..., doc. 19, p. 117; AGS, PR, leg. 49, doc. 7 (1402-IV-23, Montemor o Novo) en SuÁrez, L.: Relaciones..., doc. 31, p. 136; AGS, PR, leg. 49, doc. 3 (1402-VIII-15, Segovia) en SuÁrez, L.: Relaciones..., doc. 32, p. 156.

${ }^{57}$ AMM, CR, de 1391 a 1412, fols. 145v-146r (1411-V-30, Valladolid) en SuÁrez, L.: Relaciones..., doc. 44 , p. 175.

58 BARRIENTOS, L.: Refundición..., cap. LXXVI, p. 135.

59 AGS, PR, leg. 49, doc. 12 (1399?-XII-4, Olivenza) en SuÁrez, L.: Relaciones..., doc. 24, p. 124; AGS, PR, leg. 49, doc. 3 (1402-VIII-15, Segovia) en SuÁrez, L.: Relaciones..., doc. 32, p. 156; Lopes, F.: Crónica de D. João I, vol. II, cap. CLXXVII, p. 393; ANTT, gav. 18, maç. 11, num. 4 (1423-IV-30, Ávila) en Monumenta..., vol. III, doc. 37, p. 60.

${ }^{60}$ Lopes, F.: Crónica de D. João I, vol. II, cap. CLXXXIV, p. 407; AMB, Actas, año 1411, fol. 30r (1411-V-30, Valladolid) en Monumenta..., vol. I, doc. 152, p. 349.

${ }^{61}$ Lopes, F.: Crónica de D. João I, vol. II, cap. CLXXXIV, p. 407

${ }^{62}$ Ibid. 
-"tirar todo o debate" dios para los tirar de los dichos debates e diferencias, guerra e males" ${ }^{\prime 5}$-; pasando por la muestra de buena disposición hacia la búsqueda del acuerdo -escenificado en torno a los términos "voluntad" la abierta exaltación de la retórica del amor y de la amistad ${ }^{70}$, que cobra aquí una importancia manifiesta como firme fundamento de la unión, tanto en los momentos previos como posteriores al acuerdo -"os Reis que trautar querem de se liguar per amor" "71 "bom amorio e paz de vomtade"72, "rogándole afetuosamente" "73, "los reyes se hablaron con grande amor" $" 74$.

El acto de consecución del acuerdo quedaría referido, entre otras posibles, a través de las expresiones "venir a un acuerdo", con el uso ocasional, en el proceso mismo de negociación, de fórmulas como "ser bem visto"75, "buena fyn"76, "cheguarse a razaom aguissada"77, "devida concordança"78, "venga en conclusión"79 o "vir a boa comcordamça" ${ }^{80}$. La propia conclusión exitosa del acuerdo puede ser referida a través de expresiones como "concordado e concluido" 81 o "concordado e firmado" 82 .

${ }^{63}$ Lopes, F.: Crónica de D. João I, vol. II, cap. CLXXXI, p. 399.

${ }^{64}$ Ibid.

${ }^{65}$ ANTT, gav. 17, maç. 6, num. 16 (1480-III-6, Toledo) en As gavetas da Torre do Tombo, Lisboa, 1960-1977, 12 vols., vol. VII, no 4195, p. 292.

${ }^{66}$ (1394-III-7, Alcalá de Henares) en SuÁrez, L.: Relaciones..., doc. 7, p. 97; LoPES, F.: Crónica de D. João I, vol. II, cap. CLXXXII, p. 400.

${ }^{67}$ (1394-III-7, Alcalá de Henares) en SuÁReZ, L.: Relaciones..., doc. 7, p. 97.

${ }_{68}$ AMM, CR, de 1391 a 1412, fols. 145v-146r (1411-V-30, Valladolid) en SuÁrEz, L.: Relaciones..., doc. 44, p.176; AMB, Actas, año 1411, fol. 30r (1411-V-30, Valladolid) en Monumenta ..., vol. I, doc. 152 , p. 350 .

${ }^{69}$ Góıs, D. de: Crónica do Prínçipe D. João, Lisboa, 1977, cap. LVIII, p. 128.

70 Sobre estos aspectos, véase igualmente el apartado: "6.1. Las fórmulas de tratamiento".

${ }^{71}$ Lopes, F.: Crónica de D. João I, vol. II, cap. CLXXXIX, p. 416.

72 Ibid.

73 Valera, D. de: Memorial de diversas hazañas: Crónica de Enrique IV, ed. de J. de M. Carriazo, Madrid, 1941, cap. XLIV, p. 149.

${ }^{74}$ Ibid., cap. IX, pp. 29-30.

75 AGS, PR, leg. 49, doc. 8 (1407-VIII-16, Serra da Atougia) en SuÁrez, L.: Relaciones..., doc. 42, p. 171 .

76 AMM, CR, de 1391 a 1412, fols. 145v-146r (1411-V-30, Valladolid) en SuÁrez, L.: Relaciones..., doc. 44 , p. 176.

77 Lopes, F.: Crónica de D. João I, vol. II, cap. CXC, p. 422.

${ }_{78}$ AMM, CR, de 1391 a 1412, fols. 145v-146r (1411-V-30, Valladolid) en SuÁrez, L.: Relaciones..., doc. 44, p. 176.

79 AGS, PR, leg. 49, doc. 95 (1480-XI-[4]) en Documentos..., vol. II, doc. 274, p.125.

${ }^{80}$ Lopes, F.: Crónica de D. João I, vol. II, cap. CXC, p. 423.

${ }^{81}$ (25-II-1455, Segovia) en SousA, A.C. de: Provas..., Tomo I, Libro III, nº 56, p. 393.

82 Ibid. 
Por el contrario, el fracaso de la negociación podía ser aludido mediante la fórmula de "rehusar un acuerdo ${ }^{83}$ o los giros "partir del tracto" 84 o "quebrantar el tracto" referencia explícita a la posición de las partes, en tal situación, como "desacordados" o "desvariadas" como muestra de las tensiones propias de la negociación y de cierta renuencia hacia el pacto, cabe señalar el interés de los términos que aludirían a los procesos de "preiteiar" "desputaçoens" ", que implicaría la idea de confrontación de argumentos legales y jurídicos ${ }^{91}$, o "vía" ${ }^{22}$, entendida como una propuesta hecha por alguna de las partes dentro del proceso de negociación.

\subsection{LOS ARGUMENTOS LEGITIMADORES DEL PACTO}

El pacto, dirigido a la consecución de la paz y de la concordia, hubo de ser, en el marco de un sistema político cuya cúspide estaba constituida por una casta militar con un sistema de valores basados en la honra y el valor, necesario objeto de legitimación. Tales argumentos, en un primer término, hubieron de partir de la propia consideración de debilidad del reino, que imponía la necesidad de alcanzar un acuerdo que asegurara la suspensión temporal de la guerra, incidiendo en el propio agotamiento de este ${ }^{93}$, en la inestabilidad interna ${ }^{94} \mathrm{o}$ en el desarrollo de una iniciativa bélica paralela contra el Islam ${ }^{95}$. A tales apreciaciones se hubieron de sumar argumentos que venían

${ }^{83}$ AGS, Estado, Castilla, leg. 1-1 ${ }^{\text {o }}$, doc. 76, p. 129 (1399?-XII-20, Villanueva de Barcarrota) en SuÁrez, L.: Relaciones..., doc. 27, p. 128.

${ }^{84}$ AGS, Estado, Castilla, leg. 1-1 ${ }^{\circ}$, doc. 75 (1399?-XII-30, Villanueva de Barcarrota) en SuÁrez, L.: Relaciones..., doc. 28, p. 130; Lopes, F.: Crónica de D. João I, vol. II, cap. CLXXXIX, p. 422; Idem: Crónica de D. Fernando, cap. LVIII, p. 203.

${ }_{85}$ AMM, CR, de 1391 a 1412, fols. 145v-146r (1411-V-30, Valladolid) en SUÁREZ, L.: Relaciones..., doc. 44, p. 176; AMB, Actas, año 1411, fol. 30r (1411-V-30, Valladolid) en Monumenta..., vol. I, doc. 152 , p. 350 .

${ }^{86}$ Lopes, F.: Crónica de D. João I, vol. II, cap. CLXXXIV, p. 407.

${ }^{87}$ Ibid., vol. II, p. 424.

${ }^{88}$ AGS, PR, leg. 49, doc. 7 (1402-IV-23, Montemor o Novo) en SuÁRez, L.: Relaciones..., doc. 31, p. 135.

89 AGS, Estado, Castilla, leg. 1-1 ${ }^{\circ}$, doc. 76 (1399?-XII-20, Villanueva de Barcarrota) en SuÁrez, L.: Relaciones..., doc. 27, p. 128; Lopes, F.: Crónica de D. João I, vol. II, cap. CL, p. 330; PINA, R. de: Chronica d'El-Rei D. Affonso V, vol. III, cap. CLXXXIX, p. 94.

${ }^{90}$ Lopes, F.: Crónica de D. João I, vol. II, cap. CLXXIX, p. 396.

${ }^{91}$ Sobre la visión del "pleito" como "lid" de argumentos de tipo jurídico, véase: Lopes, F.: Crónica de D. João I, vol. II, cap. CXC, p. 425.

${ }_{92}$ AGS, Estado, Castilla, leg. 1-1 ${ }^{\circ}$, doc. 76 (1399-XII-20, Villanueva de Barcarrota) en SuÁrez, L.: Relaciones..., doc. 27, p. 128.

${ }_{93}$ Lopes, F.: Crónica de D. João I, vol. II, cap. CXLI, pp. 306-307.

${ }^{94}$ Crónicas de los Reyes de Castilla, vol. II, año 1393, cap. VI, pp. 206-207; Ibid., vol. II, año 1393, cap. XIII, p. 209.

${ }_{95}$ AMM, CR, de 1391 a 1412, fols. 145v-146r (1411-V-30, Valladolid) en SUÁrEz, L.: Relaciones..., doc. 44, p. 176; AMB, Actas, año 1411, fol. 30r (1411-V-30, Valladolid) en Monumenta..., vol. I, doc. 152, p. 350. 
a insistir en el bien supremo que representaba, en el plano teórico, la paz. Tales argumentos podían tener un carácter genérico -apelando a ideas como el provecho de los pueblos, a la unidad del pueblo cristiano o a la memoria de las antiguas paces ${ }^{96}-$, o traer a colación el argumento de autoridad, fundado sobre fuentes de la más diversa naturaleza: el Antiguo (Proverbios, Levítico, Eclesiastés, Salmos, Libro de Esther, Libro de Zacarías) y Nuevo Testamento (Evangelios, Epistolas de san Pedro, Epístolas de san Pablo), los escritos de los Padres de la Iglesia (san Agustín, san Ambrosio) o de los gentiles (Aristóteles, Séneca, Casiodoro, Cicerón). Dichas autoridades tenderán a presentar la paz y la amistad como virtud principal y engendradora de las restantes virtudes, o como bien impuesto o encomendado por Dios a los hombres ${ }^{97}$. Por la importancia teórica de tales cuestiones, las imágenes de la paz, el amor y la amistad serán esgrimidas con frecuencia no sólo para justificar la aceptación de acuerdos deshonrosos ${ }^{98}$, sino también como instrumento de presión, durante los propios procesos de negociación, hacia el reino vecino, en una búsqueda de cesiones por la parte contraria, una vez presentado el horizonte de la paz y de la amistad como meta a la que había que llegar a cualquier precio ${ }^{99}$; o, por el contrario, como elemento de resistencia frente a ciertas pretensiones aducidas en las negociaciones por la parte contraria ${ }^{100}$. Un papel creciente tuvo, en virtud de los estrechos lazos familiares que acabarían por unir a las cortes de Castilla y de Portugal, el motivo del "deudo" o "debdo"101, que remitía a una suerte de lazo de obligación impuesto en función, primordialmente, de los vínculos de parentesco, no ajeno, en ciertos casos, a la realidad de la amistad. Tal

96 Lopes, F.: Crónica de D. Fernando, cap. LIII, p. 179; Ibid., cap. LXVIII, pp. 237-238; Ibid., cap. LXIX, pp. 242-243; Crónicas de los Reyes de Castilla, vol. II, año 1411, cap. V, p. 335; Ibid., vol. II, año 1419, cap. VIII, p. 379; ANTT, gav. 17, maç. 6, num. 16 (1480-III-6, Toledo) en As gavetas..., vol. VII, n 4195, p. 288; GóIs, D. de: Crónica do Prínçipe..., cap. LVIII, p. 127.

${ }^{97}$ Invocación a estas autoridades pueden encontrarse en: ANTT, Livro das Demarcações e Pazes, fols. 142r y ss. (1431-X-30, Medina del Campo) en Monumenta ..., vol. IV, doc. 9, p. 20; AGS, PR, leg. 49, doc. 21 (1432-I-27, Almeirim) en SuÁrez, L.: Relaciones..., doc. 49, p. 183-184; Lopes, F.: Crónica de D. João I, vol. II, cap. CLXXXVIII, p. 415; Idem: Crónica de D. Fernando, cap. I, p. 13; AGS, PR, leg. 49, doc. 44 (1479-IX-4, Alcáçovas) en Documentos..., vol. I, doc. 165, p. 252; Crónicas de los Reyes de Castilla, vol. II, año 1419, cap. VIII, p. 379. Específicamente, algunas notas en la tratadística del período pueden ser encontradas en: López de Segovia, J.: De la Confederación..., pp. 17-21; VAlera, D. de: "Exortación a la pas", en Penna, M. (ed.), Prosistas..., vol. I, pp. 77-87, pp. 77-78.

98 Lopes, F.: Crónica de D. João I, vol. II, cap. CLXXX, p. 399; ANTT, gav. 17, maç. 3, num. 14 (22-VIII-1454, Segovia) en As gavetas..., vol. VII, doc. 4132, p. 4. Igualmente: (25-II-1455, Segovia), Sousa, A.C. de: Provas..., Tomo I, Libro III, no 56, p. 393.

99 Lopes, F.: Crónica de D. João I, vol. II, cap. CLXXXIX, p. 416; Ibid., vol. II, cap. CXC, p. 425.

100 AGS, PR, leg. 49, doc. 85 (1485-[VIII]) en Documentos..., vol. II, doc. 359, p. 311; Archivo Histórico Nacional (AHN), Osuna, 3909-22 (1451-III-29, Santarém) en Monumenta..., vol. XI , doc. 27, p. 43.

101 Sobre la definición de dicho término, véase: Nieto, L.; Alvar, M.: Nuevo tesoro lexicográfico del Español (S. XIV-1726), Madrid, 2007, 11 vols., vol. IV, p. 3695; Alonso, M.: Diccionario Medieval Español. Desde las Glosas Emilianenses y Silenses (s. X) hasta el siglo XV, Salamanca, 1986, 2 vols., vol. II, p. 948. 
vínculo impulsará la necesidad de abordar una paz entre ambos reinos ${ }^{102} \mathrm{o}$ de otorgar auxilio al reino vecino ${ }^{103}$, entre otros aspectos.

La consolidación de la cultura del pacto como fundamento de las relaciones entre cortes en época bajomedieval desembocó igualmente en la sistematización de un conjunto de argumentos legitimadores de la falta de acuerdo o de la ruptura del mismo. Tales argumentos discurrieron, en primer lugar, en torno a la idea de la preservación de la honra y el honor del rey y del reino ${ }^{104}$, aspecto que, a decir de Fernando de Pulgar, era superior a la propia paz ${ }^{105}$, siendo presentada, en este sentido, la honra, en tanto que legitimadora de la ruptura del pacto, como un subterfugio capaz subvertir los fundamentos jurídicos del Derecho. En segundo lugar, en torno a la valoración de las propuestas presentadas por la parte contraria como inasumibles en un proceso de negociación con garantías ${ }^{106}$, bien a partir de una descalificación directa ${ }^{107} \mathrm{o}$ a través del uso de la sátira o de la ironía como instrumentos para la desvalorización de los argumentos presentados ${ }^{108}$.

\subsection{LAS MODALIDADES DEL PACTO: TREGUAS, PACES, ALIANZAS, MA- TRIMONIOS}

Podríamos diferenciar, en virtud de la duración del acuerdo, dos grandes modalidades de pacto. En primer lugar, las "treguas generales" 109 , modalidad que se hubo de imponer durante los años posteriores a 1385 y hasta 1431, en estrecha conexión con las

102 Lopes, F.: Crónica de D. Fernando, cap. I, p. 13; Pulgar, F. de: Crónica de los Reyes Católicos, edición de J. de M. Carriazo, Madrid, 1943, 2 vols ., vol. I, cap. XXX, p. 97; ZurarA, G.E. de: Crónica..., cap. V, p. 49.

103 Lopes, F.: Crónica de D. João I, vol. II, cap. CXCVI, p. 442; GóIs, D. de: Crónica do Felicíssimo Rei D. Manuel, ed. de D. Lopes, Coimbra, 1949, 4 vols., vol. I, cap. XIX, p. 40.

104 Lopes, F.: Crónica de D. João I, vol. I, cap. LVI, p. 111; Ibid., vol. II, cap. CLXXXIV, p. 407; Ibid, vol. II, cap. CXC, p. 426; Crónicas de los Reyes de Castilla, vol. II, año 1393, cap. VIII, p. 206; PInA, R. de: Crónica de D. João II, ed. de L. de Alburquerque, Lisboa, 1989, cap. VIII, p. 19.

105 Pulgar, F. de: Crónica..., vol. I cap. II, p. 12. Algunas notas sobre esta noción en: Saraiva, A. J.: "Historiografia e honra", en O crepúsculo da Idade Média em Portugal, Lisboa, 1998, pp. 248-265, pp. 253-255, con la cual aparece estrechamente relacionada la de "vergüenza", sobre la cual es de interés: CACHO, J.M.: "La vergüenza en el discurso del poder laico desde Alfonso X a don Juan Manuel", en Actas del VI Congreso Internacional de la Asociación Hispánica de Literatura Medieval, Alcalá de Henares, 1997, 2 vols., vol. I, pp. 393-411.

106 Lopes, F.: Crónica de D. João I, vol. II, cap. CLXXXI, p. 401; Ibid., vol. II, cap. CLXXXIV, pp. 406-407; Ibid., vol. II, cap. CLXXXIX, p. 419.

107 Lopes, F.: Crónica de D. João I, vol. II, cap. CLXXXI, p. 401; Ibid., vol. II, cap. CLXXXIV, p. 407; Ibid., vol. II, cap. CLXXXIX, p. 419; PINA, R. de: Crónica de D. João II, cap. VIII, p. 20; Resende, G. de: "Vida e Feytos...", cap. CLXVI, p. 243; AGS, PR, leg. 49, doc. 85 (1485-[VIII]) en Documentos..., vol. II, doc. 359, p. 311; Pulgar, F. de: Crónica..., vol. I, cap. XXX, p. 97; Crónicas de los Reyes de Castilla, vol. II, año 1423, cap. II, p. 423.

108 Lopes, F.: Crónica de D. João I, vol. II, cap. CXC, p. 426; Ibid., vol. II, cap. CLXXVIII, p. 394; Resende, G. de: "Vida e Feytos...", cap. CLXVI, p. 243.

109 AGS, Patronato Real (PR), leg. 49, doc. 1 (1393-III-01, Lisboa) en SuÁrez, L.: Relaciones..., doc. 2 , p. 72 . 
reivindicaciones de los reyes de Castilla al trono lusitano ${ }^{110} \mathrm{y}$ acaso bajo la presión de algunos sectores que, todavía con el recuerdo presente de la derrota en Aljubarrota, eran renuentes a un acuerdo definitivo ${ }^{111}$. Hecho al que tal vez, como ha sugerido Pedro Soares Martínez, se podría sumar la influencia de los emigrados portugueses en la Corona de Castilla ${ }^{112}$. Tales treguas fueron con frecuencia revalidadas y renovadas, buscando garantizar una paz temporal que permitiera la negociación de cuestiones de mayor alcance ${ }^{113}$. No obstante, la larga duración de las mismas llevó a que, como sucedió con las firmadas en 1423, fueran percibidas como una suerte de paces ${ }^{114}$. En segundo lugar, los "tratados de paz"115 o "tratos de paces" 116 , cuyos grandes hitos cabe encontrarlos en los ya referidos acuerdos de 1431 y 1479. Tales tratos tenían, frente a la figura de la tregua, un componente duradero ${ }^{117}$, siempre que las partes respetaran los mismos, no siendo extraño que, en la consignación escrita del acuerdo, el término "paz" se acompañara de calificativos dirigidos a especificar la larga duración de la misma, como "paaz por sempre"118, "perpetua paz"119 o "pazes perpetuas e sin limitaçión de tienpo alguno, o por tienpo luenguisimo o luengo" 220 . En tercer lugar, las alianzas, referidas en algún caso como "cõfederaçam de amigos damigos, \& imigos de imigos" 121 , que bien podían actuar como complemento de un tratado de paz, es decir, la "paz con alianza", o de un matrimonio, es decir las "confederaçoeēs e alianças que (....) se avían de firmar e assentar por causa do dicto casamento"122. Tales alianzas tenían una orientación preferentemente ofensiva y defensiva, pues, como indicaba el teórico Juan López de Segovia, se harían siempre "en perjuicio y perturbación de otros" 123 , es decir, frente a un tercer reino o ciertas facciones internas, contemplando prioritariamente la fijación de ayuda de tipo militar ${ }^{124}$. En cuarto lugar, la concerta-

110 Crónicas de los Reyes de Castilla, vol. II, año 1411, cap. V, p. 335.

111 Ibid., vol. II, año 1431, cap. XXV, p. 501.

112 Martínez, P.S.: História Diplomática de Portugal, Lisboa, 1985, p. 62.

113 AMM, CR, de 1391 a 1412, fols. 18r-19r (1399-VI-4, Segovia) en SuÁrez, L.: Relaciones..., doc. $\mathrm{n}^{\circ}$ 19, p. 117; AGS, PR, leg. 49, doc. 11 (1406-IX-21, Santarem) en SuÁrez, L.: Relaciones..., doc. $\mathrm{n}^{\circ}$ 41, p. 169.

114 Crónicas de los Reyes de Castilla, vol. II, año 1423, cap. II, p. 423; Ibid., vol. II, año 1431, cap. IV, p. 491.

115 AGS, PR, leg. 49, doc. 7 (1402-IV-23, Montemor o Novo) en SuÁrez, L.: Relaciones..., doc. $n^{\circ}$ 31, p. 135.

116 AGS, PR, leg. 49, doc. 44 (1479-IX-4, Alcáçovas) en Documentos..., vol. I, doc. 165, p. 282.

117 Cf. Crónicas de los Reyes de Castilla, vol. II, año 1411, cap. V, p. 335.

118 Lopes, F.: Crónica de D. João I, vol. II, cap. CLXXVII, p. 392; Ibid., vol. II, cap. CLXXXI, p 399; Ibid., vol. I, cap. CXCV, p. 441.

119 Lopes, F.: Crónica de D. João I, vol. II, cap. CLXXVII, p. 392; Ibid., cap. CLXXXIX, p. 416; Crónicas de los Reyes de Castilla, vol. II, año 1411, cap. V, p. 335; Ibid., vol. II, año 1418, cap. IV, p. 375; ANTT, gav. 17, maç. 6, num. 116 (1480-III-6, Toledo) en As gavetas..., vol. VII, nº 4195, pp. 286 , 288.

${ }^{120}$ AGS, PR, leg. 49, doc. 44 (1479-IX-4, Alcáçovas) en Documentos..., vol. I, doc. 165, p. 248.

121 Góis, D. de: Crónica do Felicíssimo..., vol. I, cap. XIX, p. 40.

${ }^{122}$ AGS, PR, leg. 49, doc. 39 (1465-IX-12, Guarda) en Documentos..., vol. I, doc. 10, pp. 43-44.

${ }_{123}$ López de Segovia, J.: De la Confederación..., p. 21.

124 Cf. Lopes, F.: Crónica de D. João I, vol. II, cap. CXCIII, pp. 433-435 ; Idem: Crónica de D. Fernando, cap. LXXXII, p. 285; AGS, PR, leg. 49, doc. 39 (1465-IX-12, Guarda) en Documentos..., vol. 
ción de matrimonios que, en su condición teórica de sacramento indisoluble, a la vez que creador de lazos familiares entre cortes, hubo de ser visto como el sello más firme y duradero de los acuerdos políticos ${ }^{125}$, gozando tal recurso durante el reinado de los Reyes Católicos de un interés claro, al permitir la definición de una triple alianza de la monarquía hispánica con Portugal, Inglaterra y Borgoña ${ }^{126}$.

\subsection{EL ESPACIO DE LA NEGOCIACIÓN}

El ámbito cortesano fue el espacio por excelencia de la escenificación del pacto. Junto a la sala de las residencias palatinas -en las que tendría lugar la recepción de embajadores ${ }^{127}$ - y otros espacios de carácter más reservado -donde se desarrollarían las negociaciones propiamente dichas-, los espacios religiosos cortesanos hubieron de tener un papel de interés, en atención al relieve que, en el marco de las relaciones diplomáticas tardomedievales, se concedía al juramento ${ }^{128}$ y a la capacidad de tales ámbitos sagrados para otorgar implícitamente una firmeza adicional a los compromisos alcanzados ${ }^{129}$.

Además de estos espacios, cabría hablar de la definición de ámbitos espaciales específicamente destinados al desarrollo de tales prácticas. Dichos ámbitos se caracterizarían por su neutralidad simbólica ${ }^{130}$, no siendo ajena su elección, en algún caso, quizás a motivaciones de carácter práctico. Cabe citar, dentro de estos espacios, en

I, doc. 10, pp. 43-44, 49-55; AGS, PR, leg. 47, doc. 17 (1382-XII-9, Pinto) en SuÁRez, L.: Historia del reinado de Juan I, Madrid, 1977-1982, 2 vols., vol. II, doc. 320, p. 472; AGS, PR, leg. 47, doc. 44 (fols. 6-7v) (ca. 1382-IX-13/1382-XII-9) en ArNAut, S.D.: A crise..., doc. 21, pp. 341-342.

${ }^{125}$ Lopes, F.: Crónica de D. João I, vol. II, cap. CLXXXVIII, p. 415; Ibid., vol. II, cap. CXCVII, p. 445; Lopes, F.: Crónica de D. Fernando, cap. LIII, p. 181; Ibid., cap. LXVIII, p. 238; Ibid., cap. CLVII, p. 546; Ibid., cap. CLXV, pp. 568-569; Crónicas de los Reyes de Castilla, vol. II, año 1382, cap. IV, p. 78; VAlera, D. de: Crónica..., cap. IV, p. 13; PINA, R. de: Crónica de D. João II, cap. XLIV, p. 84; AGS, PR, leg. 47, doc. 46 (1383-IV-2) en Arnaut, S.D. : A crise nacional dos fins do século XIV. I. A sucessão de D. Fernando, Coimbra, 1960, doc. 26, p. 357.

126 Cf. Pérez, J.: "Los hijos de la Reina: la política de alianzas", en Isabel la Católica: reina de Castilla, Barcelona, 2002, pp. 53-84.

127 D. Duarte: Leal conselheiro, cap. LXXXI, p. 294. Cf. Silva, J.C.V. da: Paços medievais portugueses, Lisboa, 2002, p. 28, con buenos ejemplos en el ámbito palatino castellano en los conocidos tradicionalmente bajo la denominación de "salón de embajadores" en los Reales Alcázares de Sevilla o Segovia. Cf. Merino, J.M.: El Alcázar de Segovia, León, 2000, p. 81; Hernández, J.C.; Morales, A.J.: The Royal Palace of Seville, Londres, 1999, p. 58.

128 Sobre estos véase: Nieto, J.M.: Ceremonias de la realeza. Propaganda y legitimación en la Castilla Trastámara, Madrid, 1993, pp. 59-68, 89; Idem: Iglesia y génesis del Estado Moderno en Castila (1369-1480), Madrid, 1993, p. 229; Prodi, P.: Il sacramento del potere. Il giuramento político nella storia constituzionale dell' Occidente, Bolonia, 1992; MARTins, M.: "O juramento sobre a hóstia, em Fernão Lopes e na Batalha de Alfarrobeira", en Revista Portuguesa de História (Coimbra), 16 (1976), pp. 297-302, pp. 297-301; CARRASCO, A.I.: "Palabras y gestos de compromiso: los reyes castellanos y sus juramentos (siglo XV)", en E-Spania: Revue Électronique d'Études Hispaniques Médiévales (París), no 4 (2007) [en línea], puesto en línea 30 junio 2011, consultado el 20 de agosto de 2011. URL: <http://espania.revues.org/20461>.

129 PInA, R. de: Crónica de D. João II, cap. IX, p. 23.

${ }^{130}$ Cf. Lopes, F.: Crónica de D. João I, vol. II, cap. CLXXXVIII, p. 414. 
primer lugar, los territorios que actuaban como frontera entre ambas coronas ${ }^{131}$. En segundo lugar, las riberas de los ríos Duero, Tajo o Guadiana, en relación con las cuales se elegirían como espacio de negociación diversas islas fluviales o los propios cauces de los ríos, haciendo uso de barcas ${ }^{132}$. En tercer lugar, con ocasión de procesos que quizás se preveían prolongados -como las comisiones destinadas a la fijación de las reparaciones de guerra-, la estancia alterna en ciudades fronterizas castellanas y portuguesas ${ }^{133}$. Por último, villas o ciudades cercanas a la frontera, empleadas en relación con procesos como la entrega de infantas para su casamiento en el reino vecino o la fijación de tercerías. Un papel de interés hubieron de tener, en este sentido, las villas y ciudades de Moura, "que he junto do estremo"134, Ceclavin, "que es en la frontera de Portugal" 135 , o Badajoz, de la que se señala que "estava no estemos de Regnos" y no "na metade delles"136, que distaba "huũa leguoa do estremo"137, que era "cidade de seu rregno acerqua do estremo"138 o que estaba "logar frontero de Castilla"139.

131 AGS, PR, leg. 49, doc. 14 (1407-IX-5, Albergaria) en SuÁREZ, L.: Relaciones..., doc. no 43, pp. 172, 174; Lopes, F.: Crónica de D. João I, vol. II, cap. CLXXXVIII, p. 413; AGS, PR, leg. 49, doc. 66 (1479-X-5, Almaraz) en Documentos..., vol. I, doc. 191, p. 391; AGS, PR, leg. 50, doc. 24 (1490-IV18, Sevilla) en Documentos..., vol. II, doc. 422, p. 374; Crónicas de los Reyes de Castilla, vol. II, año 1392, cap. XVI, p. 201. Sobre la frontera hispano-portuguesa en época medieval véase: MARTíN, J.L.: "La frontera hispano-portuguesa en la guerra, en la paz y el comercio", en Las relaciones entre Portugal y Castilla en la época de los descubrimientos y la expansión colonial, Salamanca, 1994, pp. 29-51; Idem: "Notas sobre la frontera medieval entre Portugal y Castilla", en 1383-1385 e a Crise Geral..., pp. 155-163; Gomes, R.C.: "A construção das fronteiras", en A memoria da Nação, Lisboa, 1991, pp. 357-382; Magalhães, J.R.: "Fronteras y espacios: Portugal y Castilla”, en Las relaciones entre Portugal y Castilla en la época de los descubrimientos y la expansión colonial, Salamanca, 1996, pp. 91-101.

132 Lopes, F.: Crónica de D. Pedro I, cap. XLI, p. 188, Crónicas de los Reyes de Castilla, vol. II, año 1373, cap. VII, p. 17; Lopes, F.: Crónica de D. João I, vol. II, cap. CLXXVII, p. 393; Idem: Crónica de D. Fernando, cap. LXXXIII, p. 289; Ibid., cap. LXXXIII, pp. 290-291; GóIs, D. de: Crónica do Prínçipe..., cap. LXXV, p. 159; Crónica do Condestável de Portugal D. Nuno Álvares Pereira, ed. de A. M. de Faria, Lisboa, 1972, cap. LXXII, p. 219; VAlerA, D. de: Crónica ..., cap. XX, p. 67; ANTT, gav. 14, maç. 5, num. 3 (1411-VII-6) en As gavetas..., vol. III, doc. 2854, p. 678; PINA, R. de: Chronica d'ElRei D. Affonso V, vol. III, cap. CLXXXIX, p. 93; Ibid., vol. III, cap. CCIX, p. 144.

133 ANTT, gav. 18, maç. 11, num. 4 (1423-IV-30, Ávila) en Monumenta..., vol. III, doc. 37, p. 62.

134 Resende, G. de: "Vida e Feytos...", cap. CXIIII, p. 150.

135 ANTT, gav. 17, maç. 1, num. 9 (1497-VIII-11, Medina del Campo) en As gavetas..., vol. VI, doc. 4080, p. 487.

${ }^{136}$ Lopes, F.: Crónica de D. João I, vol. II, cap. CLXXVIII, p. 395.

137 Ibid., vol. II, cap. LIII, p. 142.

${ }^{138}$ López, F.: Crónica de D. Fernando, cap. CLXIII, p. 563.

139 Crónicas de los Reyes de Castilla, vol. II, año 1384, cap. IV, p. 89. 


\section{LOS OFICIALES DE LA DIPLOMACIA}

La casi totalidad de la acciones diplomáticas recayeron sobre los llamados "tractadores"140, "procuradores"141, "mensageros"142 $\mathrm{o}$, más frecuentemente, sobre los "embaxadores", término este último que no es raro que aparezca formando par con otros términos como "procurador"143 o "mensajero"144.

Tales términos implicarían matices específicos en atención a sus funciones y, especialmente, a sus prerrogativas ${ }^{145}$. Un conjunto característico de cargos hubo de surgir a lo largo de nuestro período de estudio, alcanzando una plena difusión en las cortes de Juan I de Portugal y de Juan II de Castila ${ }^{146}$ : los oficiales de armas. Genérico término bajo el que se habrían de incluir los heraldos, reyes de armas, trompetas y otros cargos afines, estrechamente conectados con los actos de la caballería y el universo emblemático. Tales cargos tendrían en las cortes tardomedievales la misión de "preceder una embajada, asegurar su inmunidad, pregonar su presencia o simplemente ejercer por su cuenta alguna misión más espectacular"147. Estos, entre otros aspectos, tenderían a exteriorizar la dimensión caballeresca de las relaciones internacionales, insertando los mecanismos propios del Derecho civil y consuetudinario en el ordenamiento de la caballería ${ }^{148}$.

Además de su interés instrumental desde el punto de vista diplomático, se hubo de conceder a todo este conjunto de cargos una capacidad de representación de la figura del rey, sustitutiva simbólicamente hablando de su persona en las negociaciones y manifestación, a su vez, de su poder y dignidad fuera del reino ${ }^{149}$. Tal hecho, al me-

140 AGS, PR, leg. 49, doc. 14 (1407-IX-5, Albergaria) en SuÁREz, L.: Relaciones..., doc. nº 43, p. 172; Lopes, F.: Crónica de D. João I, vol. II, cap. CLXXXVIII, p. 413.

141 Lopes, F.: Crónica de D. Fernando, cap. I, p. 12.

142 AMM, CR, de 1391 a 1412, fols. 145v-146r (1411-V-30, Valladolid) en SuÁrez, L.: Relaciones..., doc. $n^{\circ}$ 44, p. 175; Lopes, F.: Crónica de D. João I, vol. II, cap. CXLIX, p. 325; AGS, PR, leg. 47, doc. 43b (1383-I-24, Alcalá de Henares) en SuÁrez, L.: Historia del reinado..., vol. II, doc. 327, p. 488.

143 (1446-X-9, Évora) en SousA, A.C. de: Provas...Tomo I, Libro III, nº 47, p. 189; Resende, G. de: "Vida e Feytos...", cap. CLXVII, p. 243; AGS, PR, leg. 49, doc. 37 (1455-IV-16) en Documentos..., vol. I, doc. 8, p. 42.

144 AGS, PR, leg. 50, doc. 12 (1481-I-1, Moura) en Documentos..., vol. II, doc. 286, p. 143.

145 Sobre estos aspectos, es de interés: Queller, D.E.: The Office of Ambassador in the Middle Ages, Princeton, 1967.

146 Sobre estos véase: Ceballos-Escalera, A. de: Heraldos y reyes de armas en la Corte de España, Madrid, 1993; Domínguez, R.: Arte y etiqueta de los Reyes Católicos. Artistas, residencias, jardines y bosques, Madrid, 1993, pp. 655-667.

147 OchoA, M.A.: Embajadas y embajadores en la Historia de España, Madrid, 2002, p. 44.

148 Sobre este marco mental de la caballería y su relación con la cultura política, véase: RoDRÍGUEZ Velasco, J.D.: El debate sobre la caballería en el siglo XV. La tratadística caballeresca castellana en su marco europeo, Valladolid, 1996; Idem: Ciudadanía, soberanía monárquica y caballería. Poética del orden de caballería, Madrid, 2009.

149 Lopes, F.: Crónica de D. João I, vol. II, cap. CXCI, p. 429; Góis, D. de: Crónica do Felicíssimo..., vol. I, cap. XXIII, p. 46; AGS, PR, leg. 5, doc. 5 cit. en OchOA, M. A.: "Los usos diplomáticos en la época del Tratado de Tordesillas", en El Tratado de Tordesillas y su época, vol. II, pp. 801-824, p. 804; Zurara, G.E. de: Crónica..., cap. XXXII, p. 125. Cf. Pseudo-Aristóteles, Poridat de Poridades, ed. de L.A. Kasten, Madrid, 1957, p. 51; Alfonso X, Las Siete Partidas, part. II, tit. IX, ley XXI; LóPEZ DE Ayala, P.: Rimado de palacio, ed. de G. Orduna, Madrid, 1987, estrofas 617-618, p. 238. 
nos parcialmente, explicaría la elección de los cargos en atención a su "prudencia" y "autoridad" 150 , rasgos bajo los cuales aparecen caracterizados con frecuencia. El reconocimiento hacia las labores de este personal diplomático y la consolidación del mismo hubo de favorecer quizás la idea -al menos en la segunda mitad del siglo XV-, que desaconsejaba la salida del rey de sus territorios para desarrollar personalmente las negociaciones diplomáticas. Ello con el fin de guardar la honra del monarca y evitar la posibilidad de que pudiera ser capturado fuera de su reino ${ }^{151}$. Empero estas ideas, probablemente, como mediación excepcional -en contextos específicos en los que se veía peligrar el pacto ${ }^{152}$ o en los que era necesaria una alianza de forma urgente ${ }^{153}$-, con el fin de dar peso a la representación diplomática y facilitar las negociaciones, se hubo de imponer como recurso más adecuado la negociación directa del rey o de su consorte con el monarca vecino. Junto al papel de estos cargos diplomáticos en los procesos de representación del poder regio, cabe señalar el interés propagandístico que ciertos testimonios otorgarían a la apariencia externa y características formales del documento cancilleresco ${ }^{154}$.

Todos estos cargos diplomáticos se caracterizaron, salvo excepciones, por su carácter no permanente y por la no especialización en sus funciones, siendo estas generalmente encomendadas a individualidades de la corte o del reino ${ }^{155}$. Cabe pensar, como ha señalado Miguel Ángel Ochoa Brun, en la estrecha relación existente entre la presencia de una corte itinerante y la designación de embajadas temporales ${ }^{156}$, que seguirán siendo, una vez dado el salto hacia las embajadas permanentes durante el reinado de los Reyes Católicos, el instrumento habitual de comunicación diplomática con la corte portuguesa, debido a la cercanía entre ambos reinos ${ }^{157}$. Tales funciones diplomáticas -como ha señalado Isabel Beceiro, a partir del estudio realizado del perfil de setenta y tres representantes luso-castellanos entre el período 1392-1455-

${ }^{150}$ BeCEIro, I.: "La importancia de la cultura en las relaciones peninsulares (siglo XV)", en Anuario de Estudios Medievales (Madrid), 29 (1999), pp. 79-104, pp. 99-103.

151 GóIs, D. de: Chronica do Prinçipe..., cap. LXXXVIII, p. 182; PINA, R. de: Chronica d'El-Rei D. Affonso V, vol. III, cap. CCVI, p. 131, con referencia específica a la incoveniencia de comunicar directamente el rey los desafíos, "ca no sería cosa guisada de ir desafiarlo él por sí mesmo", en VALERA, D. de: "Tradado de las armas", en: Penna, M. (ed.), Prosistas..., vol. I, pp. 117-139, p. 122. Referencias al riesgo de captura del rey de Portugal en su viaje a Castilla en 1498 en: Resende, G. de: "A entrada del Rey Dom Manoel em Castella", en Cronica de D. João II..., pp. 297-318, pp. 297, 316.

152 AMM, CR, de 1391 a 1412, fols. 145v-146r (1411-V-30, Valladolid) en SuÁrEZ, L.: Relaciones..., doc. $\mathrm{n}^{\circ} 44$, p. 176 .

153 AGS, PR, leg. 49, doc. 39 (1465-IX-12, Guarda) en Documentos..., vol. I, doc. 10, p. 43; PULGar, F. de: Crónica..., vol. I, cap. XIII, p. 46; PINA, R. de: Chronica d'El-Rei D. Affonso V, vol. III, cap. CLIV, p. 43; Ibid., vol. III, cap. CLVIII, p. 51.

${ }^{154}$ López de Ayala, P.: Rimado..., estrofa 619, p. 238; Pseudo-Aristóteles: Poridat..., p. 50; Libro de los cien capitulos (Dichos de sabios en palabras breves e complidas), ed. de M. Haro Cortés, Fráncfort del Meno, 1998, cap. XVIII, p. 108.

155 Homen, A.L.C.: "Diplomacia e burocracia nos finais da Idade Media. A propósito de Lourenço Anes Fogaça, chanceler-mor (1374-1399) e negociador do Tratado de Winsor", en Estudos e ensaios em homenagem a Vitorino Magalhães Godinho, Lisboa, 1988, pp. 217-228, pp. 218-219; DíAz, L.V.: “Castilla, 1280-1360, ¿Política exterior o relaciones accidentales?”, en Génesis medieval del Estado Moderno: Castilla y Navarra (1250-1370), Valladolid, 1987, pp. 138-143, pp. 145-146.

156 ОсноА, M. А.: Embajadas..., pp. 44-45.

157 Idem: "Los usos diplomáticos...", p. 822. 
hubieron de recaer entre los miembros del Consejo Real, con presencia mayoritaria, tanto por el lado castellano como portugués, de los letrados juristas, acompañando a eclesiásticos $\mathrm{y}$, sobre todo, a caballeros, que asumirían la jefatura de las embajadas ${ }^{158}$. A partir de la década de 1420, en el marco del creciente protagonismo alcanzado por los nuevos oficiales vinculados a la cancillería, comenzaron a adquirir un creciente protagonismo los secretarios y especialmente los notarios reales castellanos en las negociaciones con Portugal ${ }^{159}$. La elección de los mismos, según Beceiro, vendría dada por "la relación entre un personaje y su cargo con el tema concreto de una misión, su experiencia en representaciones diplomáticas entre los dos países o con otros reinos europeos, su formación intelectual, especialmente en derecho civil, y su pertenencia al Consejo Real o a otros organismos de la administración del reino" 160 .

El conocimiento de los enviados en la lengua franca diplomática, el latín, no hubo de ser seguramente un requisito necesario en nuestro ámbito de análisis, en atención a la presencia persistente de las lenguas vernáculas en la documentación relativa a las relaciones entre ambos reinos conservada. Incluso acaso, al menos, en los momentos finales de la Edad Media, no hubo de ser imprescindible, al menos para los representantes castellanos, conocimientos profundos de la lengua vecina, a tenor del carácter bilingüe de ambas cortes y de la amplia presencia del castellano en la cultura cortesana portuguesa, que se hace evidente, al menos, a partir del siglo XV, prolongándose y afianzándose en el siglo XVI ${ }^{161}$, hecho que no evitó ciertas fricciones -por motivos lingüísticos, no ajenos quizá a ciertas nociones políticas e identitarias- entre los representantes de ambas cortes ${ }^{162}$.

${ }^{158}$ Cf. Beceiro, I.: "La consolidación del personal diplomático entre Castilla y Portugal (1392-1455)", en La Península Ibérica en la Era..., vol. II, pp. 1735-1744, pp. 1735-1736. Referencia específica a la participación eclesiástica en las embajadas castellanas remitidas a la corte portuguesa en época Trastámara en: Villarroel, Ó.: "Eclesiásticos en la diplomacia castellana en el siglo XV", en Anuario de Estudios Medievales (Madrid), 40:2 (2010), pp. 791-819, pp. 806-807.

159 CAÑAs, F. de P.: "La diplomacia castellana durante el reinado de Juan II: la participación de los letrados de la cancillería real en las embajadas regias", en Anuario de Estudios Medievales (Madrid), 40:2 (2010), pp. 691-722, p. 694, 713-714, con especial atención a las relaciones con Portugal en: Ibid., pp. 707-710. Treinta años después, aproximadamente desde 1450, sitúa Saul António Gomes el claro predominio de cargos laicos en las embajadas portuguesas. Cf. Gomes, S.A.: D. Afonso V..., p. 147.

${ }^{160}$ Beceiro, I.: "La consolidación...", p. 1744.

${ }^{161}$ Buescu, A. I.: “'Y la Hespañola es fácil para todos'. O bilinguismo, fenómeno estrutural (séculos XVI-XVIII)", en Memória e poder. Ensaios de história cultural (séculos XV-XVIII), Lisboa, 1999, pp. 49-66, especialmente pp. 51-58; Gavilanes Laso, J.L.: "Introducción", en Historia de la Literatura portuguesa, Madrid, 2000, pp. 11-43, pp. 37-40.

162 Dos ejemplos en: GóIs, D. de: Crónica do Felicíssimo..., vol. III, cap. LV, p. 209; ANTT, gav. 17, maç. 2, num. 23 (1509-X-6, Lisboa) en As gavetas..., vol. VI, doc. 4117, pp. 646-647. Sobre la prevenciones frente al uso del castellano en la cancillería portuguesa, en el marco de la posible unión de Portugal y de Castilla bajo la figura del príncipe D. Miguel, véase: (1499-III-27, Lisboa), ANTT, gav. 13, maç. 2, num. 4 en As gavetas..., vol. III, doc. 2538, p. 5. 


\section{LA REPRESENTACIÓN DEL PACTO}

\subsection{LAS FÓRMULAS DE TRATAMIENTO}

Las fórmulas de tratamiento -sujetas a no pocos formulismos impuestos en las prácticas cancillerescas ${ }^{163}$, en el marco de lo que se ha venido denominando como estilo cortés ${ }^{164}$ - constituyeron una clara muestra de la voluntad de entendimiento, al margen de la emotividad sincera que pudiera subyacer en las mismas. Tales prácticas, desde una perspectiva lingüística, permitirían conceptualizar la cortesía como "el conjunto de estrategias que desarrolla el hablante para evitar el conflicto con el interlocutor", a la vez que, en atención a los "aspectos sociales y convencionalizados, permiten que los miembros de un grupo mantengan una interacción fluida" 165 . En nuestro caso de análisis, la aproximación a tales fórmulas permite reconocer, a grandes pinceladas, el vaivén de las relaciones entre ambas cortes, que van desde el patente clima de hostilidad de fines del siglo XIV -cuando ambas cancillerías se refieren al rey vecino como "adversario"- hasta un deseo de entendimiento abierto a lo largo del siglo XV. Cabría agrupar estas fórmulas de cortesía en tres grandes campos temáticos: en primer lugar, la retórica familiar ("thio", "sobrino", "bom divydo", "bom parente"), en ocasiones entrando en el terreno de la familiaridad simbólica impuesta por la cercanía afectiva y jerárquica ("irmão") o por lazos de matrimonio ("fijo", "padre e madre"). En segundo lugar, la retórica exaltatoria ("muy alto", "muy excelente príncipe", "muyto poderosso prinçipe", "por la gracia de Deus rey de Castella e de Lion", "noble rey", "senhor", "muy esclarecido", "serenisimo"), como muestra de firme reconocimiento del poder y de la soberanía ejercida por el rey vecino y de sus altas cualidades personales. Tales fórmulas, que ordinariamente tendrían una función específicamente retórica, en el marco de la definición de una línea de solidaridad con el rey vecino de carácter horizontal y simétrico ${ }^{166}$, adquirirán un papel legitimador en ciertos supuestos, como ha sido apuntado en relación con el reconocimiento internacional del Maestre de Avís como rey de Portugal ${ }^{167}$. En tercer y último lugar, la retórica del amor ("muyto amado", "muy charo", "prezado", "amigo", "espeçial amigo", "muito me praz de vos veer", "se hablaron con grande amor"). Esta retórica del amor se convertirá en uno de los instrumentos de mayor interés para la expresión del acuerdo y de la unión, en el

${ }_{163}$ Diversos formularios de tratamiento se conservan para las cancillerías castellana y portuguesa del cuatrocientos en: DiAs, J.J.A. (ed.): Livro dos conselhos de El-Rei D. Duarte, Lisboa, 1982, no 50, pp. 181-200; "Livro Vermelho do Senhor Rey D. Affonso V", en Collecçaõ de livros ineditos de Historia portugueza, Lisboa, 1790-1824, 5 vols., vol. III, doc. 3, pp. 402-419; Formulario de documentos reales de la época de Juan II, Real Biblioteca (RB), II/2988, fols. 1r-4v; Archivo de la Corona de Aragón (ACA), Real Cancillería (RC), Registros (Reg.), no 3605, fols. 169v-170r en Torre, A. de la (ed.): Documentos sobre las relaciones internacionales de los Reyes Católicos, Barcelona, 1949-1951, 6 vols., vol. I, Apéndice IV, pp. 456-458; ACA, RC, Reg., no 3665, fols. ar-er en ToRre, A. de la (ed.): Documentos sobre las relaciones internacionales de los Reyes Católicos, vol. II, pp. 577-587, BNP, Colección Pombalina, Cod. 443, fols. 60r-61v en Lopes De Chaves, Á.: Livro de apontamentos (14381489), Lisboa, 1983, pp. 151-152.

164 Sobre este aspecto, es de interés: RíGano, M.: Cortesía, ideología y grupos de poder. Análisis sociolingüístico del estilo cortés en el español peninsular (siglos XII a XVII), Bahía Blanca, 2007.

165 Rígano, M.: Cortesía..., p. 13.

166 Ibid., p. 19.

${ }_{167}$ Cf. Beceiro, I.: "Las negociaciones entre Castilla y Portugal en 1399”, p. 163. 
marco de la estrecha vinculación existente entre las nociones de "paz" y de "amor". En este sentido, el amor, más que presentarse propiamente como un sentimiento en sentido estricto, se ha de considerar, ante todo, como una predisposición a obrar conforme a un vínculo de claro entendimiento entre partes, a la vez que tiende a dotar al discurso político de una dimensión emotiva y familiar, susceptible de ofrecer visiones favorables que facilitaran el acuerdo y de permitir presentar intereses de naturaleza diversa bajo la impronta del sentimiento sincero ${ }^{168}$, una vez instalada la negociación en el terreno de lo emocional. Sobre este peligro ponía sobre aviso a Juan II de Casti1la Pedro Díaz de Toledo, al señalarle que "el blando fablar es así bien como el çevo que se pone en el anzuelo para tomar el pescado"169.

\subsection{LA DIMENSIÓN CEREMONIAL}

El ceremonial desplegado con ocasión de las relaciones entre reinos buscó, en sintonía con las referidas fórmulas retóricas, facilitar el pacto y favorecer cierto clima de entendimiento en torno a tres grandes líneas ceremoniales, sobre las que ofreceremos unas notas muy generales. En primer lugar, los encuentros personales entre monarcas o vistas, durante las cuales hubo de ser fundamental la exteriorización del afecto a través de los gestos de deferencia ${ }^{170}$, en contextos caracterizados por un componente festivo que buscaría escenificar ordinariamente la holganza y placer entre reyes ${ }^{171}$.

En segundo lugar, la recepción de las embajadas de negociación en la corte. El ceremonial desplegado en tales ocasiones buscaba predisponer en un sentido positivo, desde el mismo momento de su entrada en el reino, a los embajadores para la negociación ${ }^{172}$. En tales casos, en palabras de José Manuel Nieto Soria, "el aspecto ceremonial no solía pasar de ser el primer acto de un proceso más complejo en que lo ceremonial solía quedar limitado a favorecer una actitud más negociadora y menos distante"173. Este ceremonial se plasmó preferentemente en el desarrollo de un conjunto de actos desarrollados en presencia del rey y de los altos miembros de la corte $^{174}$, entre los que cabría destacar el acto de reverencia al rey y la consulta de las cartas de creencia, precedentes a las hablas propias de la negociación ${ }^{175}$. No era extra-

168 AGS, PR, leg. 49, doc. 58 (1494-V) en Documentos..., vol. II, doc. 461, p. 415; AGS, PR, leg. 49, doc. 63 (1481-X) en Documentos..., vol. II, doc. 303, p. 204; AGS, PR, leg. 49, doc. 58 (1494-V) en Documentos..., vol. II, doc. 461, p. 416; Lopes, F.: Crónica de D. João I, vol. II, cap. CLXXXIX, pp. 416-417.

169 Díaz de Toledo, P.: Proverbios de Séneca, ed. de B. A. Riss, Ann Arbor, 1985, cap. CLXV, p. 166.

170 Resende, G. de: “A entrada...”, p. 303.

171 ANTT, gav. 17, maç. 5, num. 15 (1497-VIII-11, Medina del Campo) en As gavetas..., vol. VII, doc. 4167, p. 139; Resende, G. de: “A entrada...”, pp. 304-305; Valera, D. de: Memorial..., cap. IX, pp. 29-30; Enríquez del Castillo, D.: Crónica..., cap. 55, p. 208.

172 Una buena muestra de ello puede encontrarse en: Zurara, G.E: Crónica .., cap. XXXII, p. 125.

173 Nieto, J.M.: Ceremonias..., p. 134.

174 Un ejemplo para el reinado de Juan II de Castilla en: Crónicas de los Reyes de Castilla, vol. II, año 1419, cap. VIII, p. 379.

${ }_{175}$ Algunos ejemplos sobre estas ceremonias en: LoPEs, F.: Crónica de D. João I, vol. I, cap. LVI, p. 111; Ibid., vol. II, cap. CXCII, pp. 430-431; Resende, G. de: "Vida e Feytos...", cap. CLXVII, p. 243; 
ño el reparto de regalos, buscando despertar posiciones favorables en los embajadores y proyectar imágenes sobre la franqueza y la largueza del monarca ${ }^{176}$. Tampoco el despliegue, como se muestra ampliamente en el cuatrocientos, de ciertas ceremonias caballerescas, también de otros actos festivos, buscando la exhibición del "poder regio" ${ }^{177}$, como los celebrados con ocasión de la embajada portuguesa enviada a Castilla en $1423^{178}$, del recibimiento de Fernando López de la Orden, capellán mayor de Enrique IV y embajador remitido a la corte portuguesa, en 1454, para negociar el matrimonio del rey castellano con doña Juana de Portugal ${ }^{179}$, o del casamiento "por palabras de presente" de la infanta doña Isabel con el príncipe de Portugal, don Alfonso, celebrado en Sevilla en 1490, con asistencia de los embajadores portugueses ${ }^{180}$.

En tercer lugar, los encuentros entre los representantes diplomáticos encargados de la negociación, que hubo de carecer de un ceremonial especialmente brillante, favoreciendo, por el contrario, la definición de un código gestual que buscaría exteriorizar la firme voluntad de concordia entre los encargados de la negociación a través del abrazo, del beso o de la reverencia por medio del sombrero ${ }^{181}$.

\section{CONCLUSIONES}

El interés por el recurso de la negociación y del pacto, influido probablemente por otros condicionantes de tipo ideológico, se presenta como uno más de los aspectos ligados al nacimiento del Estado moderno. No obstante, como ya señaló Joseph Strayer, los organismos destinados a la política exterior de los Estados (Guerra, Diplomacia) tuvieron un desarrollo tardío en relación con los órganos de Justicia o Hacienda ${ }^{182}$. Este proceso, desarrollado a partir de 1300 se manifestó, según Garret Mattingly, en una cierta capacidad de monopolio del rey legítimo sobre la capacidad de representación de las embajadas, que culminaría hacia 1430, cuando quedaría "ad-

Crónicas de los Reyes de Castilla, vol. II, año 1423, cap. V, p. 424; Ibid., vol. II, año 1429, cap. XLIV, p. 472; Góis, D. de: Crónica do Felicíssimo..., vol. II, cap. XIII, p. 43. Notas específicas sobre esta ceremonia en la corte de Portugal en: ANDRADA, F. de: Crónica de D. João III, parte I, cap. XXV, p. 60; A maneira que se teve por el-rei D. Manuel que Deus tem com os embaixadores do Imperador, etc., BNP, Reservados, Cod. 886, pp. 49-51; Livro Vermelho..., doc. 6, pp. 420-421.

176 Walsh, J.K. (ed.): El Libro de los doze sabios, cap. XXXVIII, p. 107; López de MendozA, I. [Marqués de Santillana]: Obras completas, ed. de A. Gómez Moreno y M.P.A.M. Kerkhof, Madrid, 1988, pp. 250-251; Zurara, G.E. de: Crónica ..., cap. XXXII, p. 127. Cf. Nieto Soria, J.M.: Ceremonias..., p. 136; Braga, P.D.: "Mecanismos de propaganda do Poder Real no reinado de D. João II. Subsídios", en Congresso Internacional Bartolomeu Dias e a sua época, Oporto, 1989, 5 vols., vol. I, pp. 263-297, p. 278.

177 Nieto Soria, J.M.: Ceremonias..., pp. 138-139.

178 Crónicas de los Reyes de Castilla, vol. II, año 1423, cap. III, p. 424.

179 Enríquez del Castillo , D.: Crónica..., cap. XIV, p. 155.

180 Pulgar, F. de: Crónica..., vol. II, cap. CCLVII, pp. 437-439; Pina, R. de: Crónica de D. João II, cap. XLIV, p. 85.

${ }^{181}$ Lopes, F.: Crónica de D. João I, vol. II, cap. CLXXVII, p. 393; Ibid., vol. II, cap. CLXXXVIII, p. 414; Crónica do Condestável de Portugal D. Nuno Álvares Pereira, cap. LXXII, p. 220.

182 Strayer, J. R.: Sobre los orígenes medievales del Estado Moderno, Barcelona; Caracas; México D.F., 1981, pp. 109-118. 
mitido que sólo las grandes potencias europeas tenían derecho al empleo de diplomáticos de alto rango" "183.

Aunque sería necesario un análisis de una mayor amplitud cronológica y exhaustividad, cabe pensar que este desarrollo diplomático hubo de venir acompañado de un cambio en las estrategias de acción del poder regio, que supo ver en las prácticas de pacto el medio más idóneo para la consecución de ciertos objetivos políticos. Tal proceso vino acompañado de un creciente protagonismo de los principios propios del campo del Derecho, en el marco de la consolidación de la figura del letrado al servicio de la monarquía.

En este contexto, las ideas de paz, amor, amistad, deudo, honra o vergüenza alimentaron buena parte del armazón retórico y emocional de las relaciones diplomáticas tardomedievales $y$, desde un punto de vista efectivo, acabaron por legitimar las mismas prácticas del pacto, facilitando el acuerdo, legitimando tanto su asentamiento como su ruptura, o imponiendo sanciones de tipo moral frente al incumplimiento del mismo. Estos conceptos, en definitiva, hubieron de favorecer una lectura particular de las relaciones políticas entre cortes, construyendo sobre argumentos caballerescos y corteses lo que era en realidad el juego político más o menos pragmático de las relaciones internacionales tardomedievales, donde el recurso al disimulo, la dilación, el silencio o la indefinición de las respuestas se habían impuesto como prácticas habituales en los procesos de negociación que se preveían complicados ${ }^{184}$. En este punto, las órdenes de caballería vinieron a ofrecer un armazón normativo a este conjunto de nociones, no sólo imponiendo estatuariamente hablando ciertos compromisos morales $^{185}$, sino también ofreciendo un marco institucional a la amistad entre reyes, a través de las prácticas de concesión de divisas vinculadas a órdenes de caballería ${ }^{186}$.

Aunque los casos considerados no dejan de ser muy específicos, cabe, al menos, preguntarse si las mujeres del entorno regio pudieron actuar como impulsoras, en su papel de medianeras, del pacto. No deja, cuanto menos, de ser llamativo el papel que pudieron tener las relaciones entre doña Felipa, mujer de Juan I de Portugal, y su hermana, doña Catalina de Lancaster ${ }^{187}$, o entre Isabel I de Castilla y su tía, doña Beatriz ${ }^{188}$, en una más fácil consecución del acuerdo, por su probablemente más fa-

183 Mattingly, G.: La diplomacia..., pp. 63-66.

184 PINA, R. de: Chronica d'El-Rei D. Affonso V, vol. I, cap. XVIII, p. 41; Ibid., vol. I, cap. LXII, p. 125; López, F.: Crónica de D. Fernando, cap. CLVI, p. 541; GóIs, D. de: Crónica do Prínçipe..., cap. LVIII, p. 127; Idem: Crónica do Felicíssimo..., vol. I, cap. XXIV, p. 50; AGS, PR, leg. 49, doc. 82 (1479IV/V) en Documentos..., vol. I, doc. 128, p. 184.

185 VAlera, D. de: Crónica..., cap. IX, pp. 27-28; Ibid., cap. IX, p. 30; Estatutos de la Orden de la Banda en Ceballos-Escalera, A.: La orden y divisa de la Banda Real de Castilla, Madrid, 1993, cap. V, p. 61 .

186 Sobre la tardía concesión de Carlos V del Toisón de Oro a Manuel I, con motivo del matrimonio del rey portugués con doña Leonor, hermana del Emperador: GóIs, D. de: Crónica do Felicíssimo..., vol. IV, cap. XXXIV, p. 89.

187 Cf. Lopes, F.: Crónica de D. João I, vol. II, cap CXC, p. 422, 425; Ibid., vol. II, cap. CXCVII, p. 446; Zurara, G.E. de: Crónica..., cap. V, p. 49; Ibid., cap. XIII, p. 74; AMB, Actas, año 1411, fol. 30r (1411-V-30, Valladolid) en Monumenta..., vol. I, doc. 152, p. 350.

188 AGS, PR, leg. 49, doc. 44 (1479-IX-4, Alcáçovas) en Documentos..., vol. I, doc. 165, p. 246, 252; Resende, G. de: "Vida e Feytos...", cap. CXIIII, p. 150; PINA, R. de: Chronica d'El-Rei D. Affonso $V$, vol. III, cap. CCVI, p. 130-131. 
vorable posición hacia la paz ${ }^{189}$ y sus vínculos familiares. También cabe interrogarse si determinados cargos religiosos -pensamos, sobre todo, en confesores y frailes mendicantes- fueron capaces de introducir ciertos matices, en una dirección favorable, en el desempeño diplomático, en oposición a los grandes prelados y nobles ${ }^{190}$. En todo caso, su participación, que ha venido siendo considerada por José Manuel Nieto como una manifestación del predomino del personalismo regio ${ }^{191}$, era una garantía del carácter secreto de la embajada ${ }^{192}$-aspecto fundamental, en ciertos supuestos, con el fin de asegurar la honra del monarca ${ }^{193}$ - y a priori, por la vinculación de estas órdenes con la predicación, del adecuado manejo de los recursos retóricos en la exposición de las "razones" y "fablas"194.

Parece claro que, a pesar de los momentos de conflicto que enfrentaron a las monarquías portuguesa y castellana a lo largo del período, en el siglo XV existía la imagen de necesario entendimiento entre ambas ${ }^{195}$, con un horizonte mental que no olvidaba, como se recoge en el tratado de Alcáçovas de 1479, el cordial clima de amistad entre ambos reinos ${ }^{196}$ y que consideraba que, incluso en los momentos más críticos de la confrontación, el rey contrincante no era sino un enemigo circunstancial ${ }^{197}$. Ello no impidió que ocasionalmente los pactos fueran rotos o los acuerdos matrimoniales quedaran sin ejecución, como reconocía el cronista castellano Alonso de Palencia ${ }^{198}$, generalmente por motivos de tipo político, que acabarían teniendo preferencia sobre los lazos familiares o de amistad ${ }^{199}$.

189 Lopes, F.: Crónica de D. João I, vol. II, cap. CXCVI, p. 444; Crónica incompleta..., cap. XXXVI, pp. 241-242.

190 AGS, PR, leg. 49, doc. 58 (1494-V) en Documentos..., vol. II, doc. 461, p. 418; AGS, PR, leg 49, doc. 76 (1480-VII-24, Toledo) en Documentos..., vol. II, doc. 250, p. 86; PINA, R. de: Crónica de D. João II, cap. VIII, p. 22; VALERA, D. de: Crónica..., p. 11.

191 Nieto, J.M.: Iglesia..., p. 142.

192 Góis, D. de: Crónica do Felicíssimo..., vol. I, cap. XLVI, p. 110; PINA, R. de: Crónica de D. João II, cap. XVIII, p. 43. Sobre este aspecto, con interés para momentos posteriores, véase: RosárIo, A. do: "Notícia de frades pregadores em serviço diplomático. Séculos XIII-XVII", en A diplomacia na História de Portugal, Lisboa, 1990, pp. 29-58; FArIA, A.M.H.L. de: "Diplomacia de guerra e missões secretas. O papel dos dominicanos no período da Restauração", en Dominicanos em Portugal. História, cultura e arte, Lisboa, 2010, pp. 191-206.

${ }_{193}$ López, F.: Crónica de D. Fernando, cap. CLIV, p. 533-534; GóIs, D. de: Crónica do Prínçipe..., cap. LVIII, p. 127; cap. LXXV, p. 159; VALERA, D. de: Crónica ..., cap. XX, p. 67.

194 Véase al respecto: Gómez Redondo, F.: "Los modelos ideológicos de la oratoria cortesana en la Edad Media castellana", en Oratoria y Literatura. Actas del IV Seminario Emilio Castelar, Cádiz, 2004, pp. $155-165$.

195 AGS, PR, leg. 49, doc. 44 (1479-IX-4, Alcáçovas) en Documentos..., vol. I, doc. 165, p. 248; AGS, PR, leg. 49, doc. 44 (1479-IX-4, Alcáçovas) en Documentos..., vol. I, doc. 165, p. 252.

196 AGS, PR, leg. 49, doc. 44 (1479-IX-4, Alcáçovas) en Documentos..., vol. I, doc. 165, pp. 248$249,250,252$.

197 Zurara, G.E. de: Crónica..., XIV, p. 76.

198 Palencia, A. de: Gesta Hispaniensia Ex Annalibvs Svorvm Diervm Collecta, ed. de B. Tate y J. Lawrance, Madrid, 1998, 2 vols., vol. I, lib. I-V, p. 30.

199 Lopes, F.: Crónica de D. João I, vol. II, cap. CXCIV, p. 438; Crónica incompleta..., cap. LV, p. 331; Rodríguez de Almela, D.: De cómo e por qué razón non se deve dividir, partir nin enajenar los regnos e señoríos de España (1482-VII-18, Murcia), en Idem: Cartas..., fol. 36v, p. 55. 